\title{
The dynamics of US inflation: can monetary policy explain the changes?
}

\author{
Fabio Canova \\ Filippo Ferroni \\ ICREA-UPF, CREI, CREMeD, AMeN and CEPR * Banque de France ${ }^{\dagger}$
}

June 22, 2010

\begin{abstract}
We investigate the relationship between monetary policy and inflation dynamics in the US using a medium scale structural model. The specification is estimated with Bayesian techniques and fits the data reasonably well. Policy shocks account for a part of the decline in inflation volatility; they have been less effective in triggering inflation responses over time and qualitatively account for the rise and fall in the level of inflation. A number of structural parameter variations contribute to these patterns.
\end{abstract}

JEL classification no: E52, E47, C53

Key words: New Keynesian model, Bayesian methods, Monetary policy, Inflation dynamics.

${ }^{*}$ I would like to thank the editor of this journal, two anonymous referees, the participants of seminars at the University of Southampton, the University of Bern, the Bank of England and the Swiss National Bank for comments and Evi Pappa for constructive suggestions on an earlier draft of the paper. The financial support of the Spanish Ministry of Education through the grant SEJ-2004-21682-E and the Barcelona Graduate School of Economics are gratefully acknowledged.

${ }^{\dagger}$ The views expressed in this paper do not necessarily reflect those of the Banque de France. 


\section{Introduction}

The US economy went through a number of important structural changes over the last forty years. For example, the level of inflation and of nominal interest rates shows an inverted Ushaped pattern, rising at the end of the 1970s and falling at the beginning of the 1980s; while the persistence and the volatility of inflation dramatically declined since the mid 1980s; see e.g. Stock and Watson (2002). These patterns are well documented in the literature. What still is to be determined are the causes of these changes.

The prevailing view suggests that the run-up of inflation occurred because monetary authorities believed that there was an exploitable trade-off between inflation and output. Since output was low following the oil shocks of the 1970s, the temptation to inflate was strong. However, the option of keeping inflation temporarily high was unfeasible: in the medium run, inflation reached a higher level with output settling at its potential. Since the 1980s, central banks learned that the output-inflation trade-off was not exploitable and concentrated on the objective of fighting inflation. A low inflation regime ensued, and the larger predictability of monetary policy made the macroeconomic environment less volatile (see e.g. Sargent (1999), Clarida, et al. (2000), and Lubik and Schorfheide (2004)). There are two alternative views to this prevailing wisdom: one focuses on "real" causes (see e.g. McConnell and Perez Quiroz (2000), Campbell and Herkovitz (2006)) and the other hinges on "good luck" (see e.g. Bernanke and Mihov (1998), Leeper and Zha (2003), Sims and Zha (2006)) to explain the changes in the level and in the autocovariance function of inflation.

One reason for this heterogeneity of explanations is that the empirical strategy used to study the issue matters. In general, VAR based evidence tends to support the good luck hypothesis; calibration exercises point to real reasons for the changes; and structural econometric analyses favor the idea that monetary policy is responsible for the observed variations (see, e.g. Ireland (2001), Lubik and Schorfheide (2004) and Boivin and Giannoni (2006)). However, while structural VAR exercises allow for time varying coefficients and variances, the evidence produced by more structural calibration or econometric analyses is mostly restricted to arbitrarily chosen subsamples. Because inflation and the nominal rate displayed an inverted U-shaped pattern, subsample evidence may depend on the selected break point. Fernandez Villaverde and Rubio Ramirez (2008) and Justiniano and Primiceri (2008) have estimated evolving structural models but their conclusions are only suggestive, because computational complexities force them to consider variations only in a subset of the parameters. Given that one expects important covariations in the evolution of structural parameters, allowing only a subset of the parameters to change may bias inference. Hence, 
it is of interest to know whether less computationally intensive and yet intuitively appealing structural methods can tell us more about the nature of the changes experienced by US inflation.

This paper provides a step in that direction by estimating a structural model over rolling samples of fixed length with Bayesian techniques. Bayesian methods, which have become popular tools to bring DSGE models to the data thanks to the work of Smets and Wouters (2003) and Del Negro and Schorfheide (2004) among others, have inferential and computational advantages over traditional limited and full information classical techniques when dealing with models which are known to be a misspecified description of the data. In these situations, unrestricted classical estimates are often unreasonable or on the boundary of the parameter space and tricks must be employed to produce economically sensible estimates. Furthermore, asymptotic standard errors attached to classical estimates - which are constructed assuming that the model is "true" - are meaningless. Rolling samples allow us to use relatively standard techniques to study the nature of the time variations present in interesting parameters while maintaining some form of rationality in the economy and computational costs manageable. For example, relative to Fernandez Villaverde and Rubio Ramirez (2008), our setup allows the use of Kalman filtering techniques in building the likelihood function and permits time covariations in all the parameters.

The specification we consider deviates somewhat from what is standard in the literature by allowing money to play a role. The stock of money has been neglected in all recent monetary policy discussions (see e.g. Woodford (2003)) and Ireland (2004) provided empirical evidence supporting this approach. In our setup real balances can potentially affect the Euler equation and the growth rate of nominal balances is allowed to enter the monetary policy rule. Since we will use loosely specified but proper priors in the estimation, the data will decide whether these and other modeling features are important in characterizing the experience. Overall, the statistical fit of the model looks satisfactory, in particular, in comparison with other structural specifications. We estimate the preferred specification a number of times over rolling samples, analyze the time evolution of interesting inflation statistics, measure the contribution of monetary policy to the observed changes and study the evolution of structural parameters.

Our model captures the fall in inflation volatility over time and part of the changes can be attributed to monetary policy shocks. We detect level but not shape differences in the transmission of policy shocks which tend to make inflation less reactive to policy disturbances as time went by. Finally, variations in the level of inflation are qualitatively related to policy shocks: had those been absent, the rise of the 1970s and the fall of 1980s 
would have been much more modest.

A number of structural changes drive these results. We find support for the conjecture that the Fed had a much stronger dislike for inflation but also noticed that in the latest samples the coefficient resembles the one obtained at the beginning of the sample. Moreover, the estimate of the long run coefficient on monetary aggregates has been steadily declining over time. In agreement with the good luck hypothesis, we detect variations in the posterior mean estimate of the variance of the policy shocks. Nevertheless, as in Sims and Zha (2006), the variations we discover are typically reversed over time. Finally, consistent with non-monetary explanations of the facts, we also find that important private sector parameters such as the slope of the Phillips curves and the costs of adjusting investment have significantly changed in the later samples.

In sum, consistent with the conclusions of Gambetti et. al. (2008), we find that a combination of causes appears to be responsible for the changes in the level and the autocovariance function of US inflation over the last forty years: changes in the variance of the shocks, in the parameters regulating private sector behavior and in the policy rule all more or less contributed to explain why inflation rose and fell, why inflation volatility subsided.

The rest of the paper is organized as follows. Section 2 describes the model, the estimation technique and the diagnostics used to evaluate the quality of the model's approximation to the data. Section 3 presents estimation results for the full sample. Section 4 reports the time profile of inflation statistics over the rolling samples. Section 5 interprets these time profiles in terms of rolling structural parameter estimates. Section 6 concludes.

\section{The framework of analysis}

\subsection{The Theoretical model}

We consider a medium scale model featuring several shocks and frictions. Households maximize a utility function which depends on three arguments (money, consumption and leisure), and money and consumption are potentially non-separable. Labor is differentiated over households, so that there is some monopoly over wages which results in an explicit wage equation. Households allocate wealth among cash and a riskless bond, and bonds demand is hit by a preference disturbance (as in Smets and Wouters (2007)). Households also rent capital services to firms and decide how much capital to accumulate. As the rental price of capital goes up, the capital stock can be used more intensively according to some schedule cost. There are two types of firms; a final good representative firm that aggregates intermediates goods, and a continuoum of intermediate producing firms that 
combine labor and capital in a monopolistic competitive market where price decisions are subject to a Calvo lottery. Prices that can not be optimally adjusted are assumed to be partially indexed to past inflation. Similarly, in the labor market unions sell differentiated units of labor in a monopolistic competitive environment with a Calvo type scheme. When unions receive positive signals, they are allowed to re-optimize wages; otherwise they adjust wages indexing them to past inflation. Finally, profits generated from the imperfectly competitive intermediate goods and the labor markets are redistributed to households. The nominal interest rate is controlled by a monetary authority who set it in reaction to inflation, output gap and real balances.

The equations we employ can be derived from first principles - optimizing and forward looking consumers and firms and general equilibrium considerations. Since derivations of this type exist in the literature (see e.g. Smets and Wouters (2003) and Ireland (2004)), we simply present the optimality conditions and highlight how they link to the objective 
functions and the constraints of the agents. The system in log-linear form is:

$$
\begin{aligned}
\omega_{1} \theta_{t} & =-c_{t}+h c_{t-1}-\omega_{2} m_{t}+\omega_{2} e_{t} \\
\omega_{3} l_{t} & =\theta_{t}+w_{t}^{H H} \\
\theta_{t} & =-\omega_{5} c_{t}+h \omega_{5} c_{t-1}-\omega_{4} m_{t}+\omega_{4} e_{t}-\frac{1}{R-1}\left(\epsilon_{t}^{b}+r_{t}\right) \\
z_{t} & =a^{\prime} / a^{\prime \prime} r_{t}^{k} \\
k_{t}^{s} & =z_{t}+k_{t-1} \\
k_{t}^{s} & =w_{t}+l_{t}-r_{t}^{k} \\
m c_{t} & =(1-\alpha) w_{t}+\alpha r_{t}^{k}-\epsilon_{t}^{a} \\
y_{t} & =\frac{\Psi}{\Psi-1} \epsilon_{t}^{a}+\frac{\Psi}{\Psi-1} \alpha\left(w_{t}-r_{t}^{k}\right)+\frac{\Psi}{\Psi-1} l_{t} \\
y_{t} & =\frac{C}{Y} c_{t}+\frac{K}{Y} \delta i_{t}+\epsilon^{g} \epsilon_{t}^{g}+\alpha z_{t} \\
k_{t} & =(1-\delta) k_{t-1}+\delta i_{t}+\delta \epsilon_{t}^{i} \\
r_{t} & =\lambda_{r} r_{t-1}+\lambda_{y} y_{t}+\left(\lambda_{p}+\lambda_{m}\right) \pi_{t}+\lambda_{m}\left(m_{t}-m_{t-1}\right)+\zeta_{t}^{r} \\
\theta_{t} & =E_{t}\left[\theta_{t+1}+\epsilon_{t}^{b}+r_{t}-\pi_{t+1}\right] \\
q_{t} & =E_{t}\left[\beta r^{k} r_{t+1}^{k}+\beta(1-\delta) q_{t+1}-\theta_{t}+\theta_{t+1}\right] \\
(1+\beta) S^{\prime \prime} i_{t} & =E_{t}\left[q_{t}+\epsilon_{t}^{i}+S^{\prime \prime} i_{t-1}+\beta S^{\prime \prime} i_{t+1}\right] \\
\left(k_{w}+\beta \xi_{w}\right) w_{t} & =E_{t}\left[k_{w}\left(w_{t}^{H H}+\frac{\epsilon^{w}}{\epsilon^{w}+1} \epsilon_{t}^{w}\right)+w_{t-1}+\beta w_{t+1}\right. \\
& \left.-\left(1+i_{w} \beta\right) \pi_{t}+i_{w} \pi_{t-1}+\beta \pi_{t+1}\right] \\
\pi_{t} & =E_{t}\left[\frac{i_{p}}{1+\beta i_{p}} \pi_{t-1}+\frac{\beta}{1+\beta i_{p}} \pi_{t+1}+k_{p}\left(m c_{t}+\frac{\epsilon^{p}}{\epsilon^{p}+1} \epsilon_{t}^{p}\right)\right] \\
& \left.=t_{t}\right)
\end{aligned}
$$

where variables with time subscript are $\log$ deviation from the steady state, and variables without are variables at the steady state. Equation (1)-(4) and (12)-(14) are derived from the household optimality conditions, where the $\omega$ 's are convolutions of steady states values and parameters that capture the curvature of the utility function. In particular, $\omega_{1}=-\frac{U_{c}}{C U_{c c}}, \omega_{2}=\frac{m U_{c m}}{C U_{c c}}, \omega_{3}=-\frac{L V_{L L}}{V_{L}}, \omega_{4}=-\frac{m U_{m m}}{U_{m}}$ and $\omega_{5}=-\frac{C U_{m c}}{U_{m}}$. Equation (1) relates the marginal utility of consumption, $\theta_{t}$, to current consumption, $c_{t}$, past consumption (controlled by a degree of habit, $h$ ), real balances, $m_{t}$, and a money demand shock, $e_{t}$. When preferences are separable in real balances and consumption, $\frac{\partial^{2} U(c, m)}{\partial C \partial m}=0$ so that $\omega_{2}=0$ and $\omega_{5}=0$ and real balances do not enter in the Euler equation. Unions pay a wage, $w_{t}^{H H}$, constant across households $(\mathrm{HH})$, which reflects the marginal rate of substitution between working, $l_{t}$, and consumption, see equation (2). Equation (3) is a money demand equation which depends on current and past consumption, the nominal interest rate, $r_{t}$, and a preference disturbance, $\epsilon_{t}^{b}$. Current capital services, $k_{t}^{s}$, are a function of the 
capital installed in the previous period, $k_{t-1}$, and the degree of capital utilization, $z_{t}$ (see equation (5)). Household cost minimization implies that the degree of capital utilization is a positive function of the rental rate of capital, as in equation (4). Equation (6) relates the capital per worker to the cost of capital, $r_{t}^{k}$, and of labor, $w_{t}$. In equation (7) the marginal cost, $m c_{t}$ is determined by the real cost of the two factors in production, $r_{t}^{k}$ and $w_{t}$, with weights given by their respective share in production, net of the total factor productivity disturbance, $\epsilon_{t}^{a}$. Final output, $y_{t}$, is produced using a Cobb-Douglas production function (see equation (8)), where $\Psi$ captures fixed cost in production, and $\alpha$ is the capital share. Total output is absorbed by exogenous government spending, $\epsilon_{t}^{g}$, by investment, $i_{t}$, by consumption, $c_{t}$, and by the capital utilization cost, $z_{t}$ (see equation (9)). New installed capital is formed by the flows of investment and the net of depreciation old capital, $(1-\delta) k_{t-1}$, see equation (10). The capital accumulation equation is hit by the investment-specific technology disturbance $\epsilon_{t}^{i}$. Equation (11) represents a policy rule. The specification is standard in the first three terms, reflecting an interest rate smoothing desire and the wish to respond to fluctuations in the output and inflation. We allow the policy rule to depend on the growth rate of nominal balances in order to mimic concerns that Central Banks had over monetary aggregates for part of the sample and let $\lambda_{m} \geq 0$. The disturbance to this equation represents a monetary policy shock which is, by construction, orthogonal to the other structural disturbances. The Euler equation, (12), controls the dynamics of consumption and real balances, where current consumption and money balances depend on their expected values and the ex-ante real interest rate, $r_{t}-E_{t} \pi_{t+1}$. Equation (13) is the Q equation that gives the value of capital stock, $q_{t}$. It states that the current value of capital stock depends positively on expected future value of the capital stock and on the real rental rate on capital and negatively on the marginal utility of consumption. Equation (14) is an investment equation: the current value of investment depends on past and expected future value of investment and on current value of the stock of capital. Equation (15) gives the dynamics of the real wage which moves sluggishly because of the wages stickiness and the partial indexation assumption; wages responds to past and future expected real wage, to the (current, past and expected) movements in inflation. Real wage depends also on the wage paid to HH by the union and on the wage markup, $\epsilon_{t}^{w}$, with slope $k_{w}=\frac{\left(1-\xi_{w}\right)\left(1-\beta \xi_{w}\right)}{\xi_{w}}$, where $1-\xi_{w}$ is the probability of re-optimize wages. Equation (16) is a New Keynesian Phillips curve: current inflation depends positively on past and expected inflation, and on marginal costs. This equation is hit by a price markup disturbance, $\epsilon_{t}^{p}$ and the slope is $k_{p}=\frac{\left(1-\xi_{p}\right)\left(1-\beta \xi_{p}\right)}{1+i_{p} \beta}$, where $\beta$ is the time discount factor, $\xi_{p}$ is the probability of keeping the prices fixed. The system is driven by 8 exogenous processes, $e_{t}=\rho_{e} e_{t-1}+\zeta_{t}^{e}$ (money 
demand), $\epsilon_{t}^{b}=\rho_{b} \epsilon_{t-1}^{b}+\zeta_{t}^{b}$ (preference), $\epsilon_{t}^{a}=\rho_{a} \epsilon_{t-1}^{a}+\zeta_{t}^{a}$ (technology), $\epsilon_{t}^{i}=\rho_{i} \epsilon_{t-1}^{i}+\zeta_{t}^{i}$ (investment specific), $\ln \widetilde{\epsilon}_{t}^{g}-\ln \epsilon^{g}=\epsilon_{t}^{g}=\rho_{g} \epsilon_{t-1}^{g}+\zeta_{t}^{g}$ (government), $\ln \widetilde{\epsilon}_{t}^{p}-\ln \epsilon^{p}=\epsilon_{t}^{p}=\rho_{p} \epsilon_{t-1}^{p}+\zeta_{t}^{p}$ (price markup), $\ln \widetilde{\epsilon}_{t}^{w}-\ln \epsilon^{w}=\epsilon_{t}^{w}=\rho_{w} \epsilon_{t-1}^{w}+\zeta_{t}^{w}$ (wage markup) and $\epsilon_{t}^{r}=\zeta_{t}^{r}$ (monetary policy shock), where the $\zeta$ 's are normal i.i.d. shocks.

We assume that the investigator observes output, consumption, investment, hours worked, real wages, real balances, the inflation rate, the nominal interest rate. The sample goes from
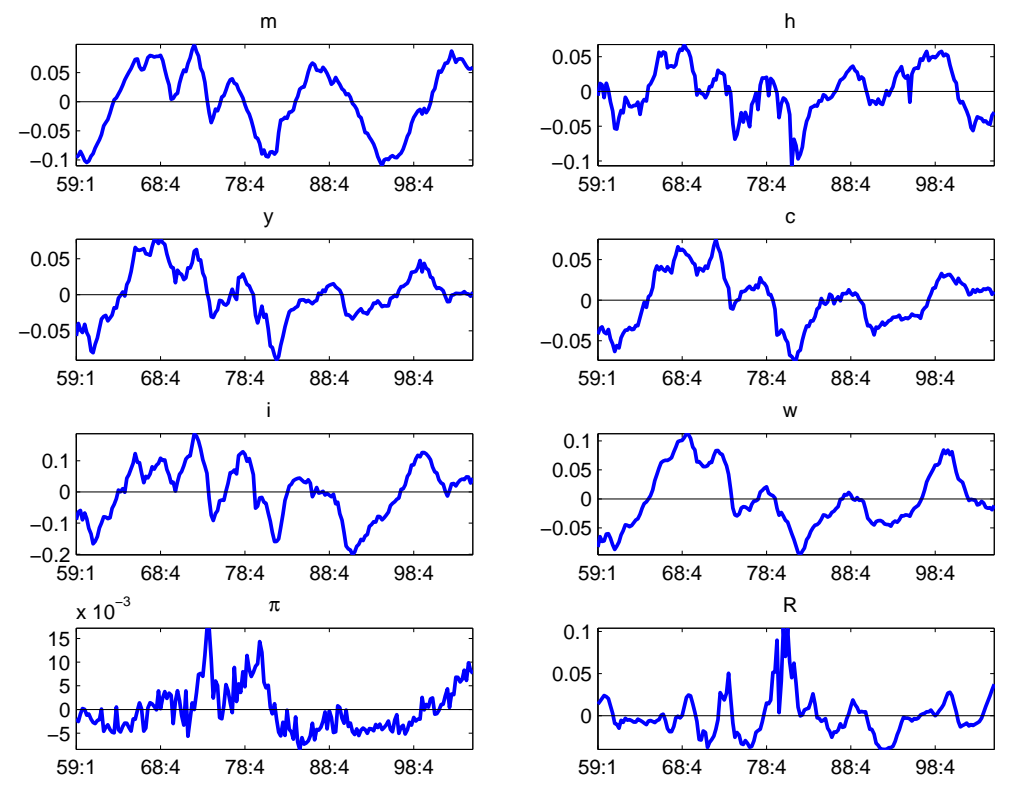

Figure 1: Data in logs. From top left, M2, hours worked, output, consumption, investment, wages, inflation and interest rate. A quadratic trend is removed from all series.

1959:1 to 2006:1 and the data is obtained from the FRED database at the Federal Reserve Bank of St. Louis. We stop at 2006 to maintain comparability with the existing literature and this avoids headaches on how deal with the recent financial crisis episode. For real balances we use real M2 (deflated by the GDP deflator). The inflation rate is measured by the growth rate of GDP deflator, the nominal rate by the Federal Funds rate and real variables are scaled by the civilian noninstitutional population (CNP16OV) to transform them in per-capita terms. Despite these transformations, some series still display an upward trends. We therefore separately eliminate it from their log using a simple quadratic specification. While the resulting fluctuations display long period of oscillation, they are overall stationary as the model assumes (see figure 1).

As a referee has pointed out, one feasible alternative to the strategy we use to match the data to the model's counterparts is to allow the cost push shocks to be non-stationary 
and remove the upward trend in output and real balances using a model consistent method. We do not follow this approach for three reasons. First, when cost push shocks have a unit root, output and real balances share the same trend, which is not the case with the available data. Second, it is unclear whether all non-cyclical fluctuations can be safely attributed to non-stationary technology shocks. For example, Chang et al. (2006) have recently fit a model with non-stationary preference shocks to US data with good results. Third, the data transformed with a model based trend still displays a clear non-stationary behavior and this makes parameters estimates unreliable and the quality of the fit quite poor.

\subsection{The prior and the estimation technique}

The model (1)-(16) contains up to 38 parameters; 18 structural ones $\eta_{1}=\left(h, \pi, \beta, a^{\prime} / a^{\prime \prime}, S^{\prime \prime}, \xi_{w}, i_{w}, \epsilon_{w}, \xi_{p}, i_{p}, \epsilon_{p}, \lambda_{r}, \lambda_{y}, \lambda_{m}, \lambda_{\pi}, \epsilon^{g}, \delta, \alpha\right), 5$ semi-structural ones $\eta_{2}=$ $\left(\omega_{1}, \omega_{2}, \omega_{3}, \omega_{4}, \omega_{5}\right)$, and 15 auxiliary ones, $\eta_{3}=\left(\rho_{e}, \rho_{b}, \rho_{a}, \rho_{i}, \rho_{g}, \rho_{w}, \rho_{p}, \sigma_{e}, \sigma_{b}, \sigma_{a}, \sigma_{i}, \sigma_{g}, \sigma_{r}, \sigma_{w}, \sigma_{p}\right)$. Our exercise is geared to obtain posterior distributions of $\eta=\left(\eta_{1}, \eta_{2}, \eta_{3}\right)$ using loosely specified but proper priors.

We assume univariate prior densities for each of the parameters even if, in principle, there should be some correlation structure among the priors. Note that, since all the priors are proper, posterior distributions are proper and various specifications can be compared with simple odd ratios. The prior shapes we use in our benchmark specification are relatively standard (see table 1), and very similar to the ones used in Smets and Wouters (2007) but with much larger prior standard deviations. We fix some parameters, time discount factor $\beta=0.995$, capital depreciation rate $\delta=0.025$, steady state government spending over GDP $\epsilon^{g}=0.18$, capital share $\alpha=0.3$, steady state inflation $\pi=1.006$ since they are not identifiable from the data we use.

The model can be solved with standard methods. Its solution has a state space format:

$$
\begin{aligned}
x_{1 t+1} & =A_{1}(\eta) x_{1 t}+A_{2}(\eta) \zeta_{t+1} \\
x_{2 t} & =A_{3}(\eta) x_{1 t}
\end{aligned}
$$

where $x_{2 t}=\left[m_{t}, h_{t}, y_{t}, c_{t}, i_{t}, w_{t}, \pi_{t}, r_{t}\right], \zeta_{t}=\left[\zeta_{t}^{e}, \zeta_{t}^{b}, \zeta_{t}^{a}, \zeta_{t}^{i}, \zeta_{t}^{g}, \zeta_{t}^{r}, \zeta_{t}^{p}, \zeta_{t}^{w}\right]$ and the matrices $A_{i}(\eta), i=1,2,3$ are complicated nonlinear functions of the $\eta$ 's.

Bayesian estimation of (17) and (18) is simple: given some $\eta$, and a sample $t, \ldots, T$, we compute the likelihood, denoted by $f\left(y_{[t, T]} \mid \eta\right)$, by means of the Kalman filter and the prediction error decomposition. Then, for any specification of the prior distribution, denoted by $g(\eta)$, the posterior distribution for the parameters is $g\left(\eta \mid y_{[t, T]}\right)=\frac{g(\eta) f\left(y_{[t, T]} \mid \eta\right)}{f(y)}$. The analytical computation of the posterior is impossible in our setup since the denominator of 
the expression, $f(y)$, requires the integration of $g(\eta) f\left(y_{T} \mid \eta\right)$ with respect to $\eta$, which is a high dimensional vector. In order to obtain draws from the unknown posterior distribution we use the following (Metropolis) algorithm:

1. Choose a $\eta_{0}$. Evaluate $g\left(\eta_{0}\right)$; use the Kalman filter to evaluate the likelihood $\mathcal{L}\left(y_{[t, T]} \mid \eta_{0}\right)$. 2. For each $i=1, \ldots, 38$ set $\eta_{i}=\eta_{i-1}$ with probability $1-p$ and $\eta_{i}=\eta_{i}^{*}$ with probability $p$, where $\eta_{i}^{*}=\eta_{i-1}+v_{i}$ and $v=\left[v_{1}, \ldots, v_{38}\right]$ follows a multivariate normal distribution and $p=\min \left\{1, \frac{\mathcal{L}\left(y_{[t, T]} \mid \eta_{i}^{*}\right) g\left(\eta_{i}^{*}\right)}{\mathcal{L}\left(y_{[t, T]} \mid \eta_{i-1}\right) g\left(\eta_{i-1}\right)}\right\}$.

3. Repeat steps 1 . and 2. $\bar{L}+L$ times and keep the last $L$ draws.

At the end of the routine one has $L$ draws to conduct the structural analysis.

Two important issues concern the convergence of simulated draws, that is, what is the size of $\bar{L}$, and the acceptance rate. We set the number of iteration to 500,000 , checked for convergence using the cumulative sum of the draws (CUMSUM) statistics and found that convergence is achieved typically after 200000 draws. For inference we discard the first half of the chain an keep one every 250 draws, so that we remove the correlation among draws and have 1000 draws from the posterior distribution to work with. To get reasonable acceptance rates, it is important to properly select the variance of $v_{i}$. If the acceptance rate is "too small" the chain will not visit the parameter space in a reasonable number of iterations. If it is too high, the chain will not stay long enough in the high probability regions. We set the variance of $v_{i}$ to target an acceptance rate in the range 20-40 percent.

The chosen prior shape reflects the restrictions on the support of the parameter space. Various parameterizations of the Beta distributions were tried and results are, by and large, insensitive to settings of the parameters controlling the location of these distributions. Finally, the choice of prior distributions for the policy parameters implies that multiple equilibria are unlikely to characterize the data.

\subsection{A measure of fit and model comparisons}

To assess the quality of our model's approximation to the data we have estimated a number of interesting structural benchmarks. In the next section, we present the marginal likelihood (ML) of our model and of alternative specifications where e.g. parameter restrictions are imposed, real balances play no role in the Euler equation, or nominal balances do not enter the policy rule, or both. For each model $\mathcal{M}_{i}$, we approximate $\mathcal{L}\left(y_{[t, T]} \mid \mathcal{M}_{i}\right)$, the marginal

likelihood of $\mathcal{M}_{i}$ using $\left[\frac{1}{L} \sum_{l} \frac{f\left(\eta_{l}^{i}\right)}{\mathcal{L}\left(y_{[t, T]} \mid \eta_{l}^{i}, \mathcal{M}_{i}\right) g\left(\eta_{l}^{i} \mid \mathcal{M}_{i}\right)}\right]^{-1}$. Following Geweke (1998), we define for some $p \in(0,1)$

$$
f\left(\eta_{l}^{i}\right)=p^{-1}(2 \pi)^{-k / 2} \exp \left[-1 / 2\left(\eta_{l}^{i}-\bar{\eta}^{i}\right) \Sigma^{i}\left(\eta_{l}^{i}-\bar{\eta}^{i}\right)^{\prime}\right]
$$


where $\eta_{i}^{l}$ is draw $l$ for the parameters $\eta$ of model $i, \bar{\eta}^{i}=\frac{1}{L} \sum_{l} \eta_{l}^{i}, \Sigma^{i}=\frac{1}{L} \sum_{l}\left(\eta_{l}^{i}-\bar{\eta}^{i}\right)\left(\eta_{l}^{i}-\bar{\eta}^{i}\right)^{\prime}$. Moreover, $\eta_{i}^{l}$ is such that $\left(\eta_{l}^{i}-\bar{\eta}^{i}\right) \Sigma^{i}\left(\eta_{l}^{i}-\bar{\eta}^{i}\right)_{p}^{\prime 2}\left(k_{i}\right)$, where $\chi_{p}^{2}\left(k_{i}\right)$ is the $p$ quantile of a chisquare distribution where $k_{i}$ is the number of parameters in model $i$.

To provide additional information on the success of the estimation process, we also examine the properties of the structural residuals and compare moments of the endogenous variables to those obtained from more unrestricted specifications. Both statistics can tell us something about specification problems of the model and therefore nicely complement what marginal likelihood comparisons give us.

\section{$3 \quad$ Full sample estimation and specification searches}

We start estimating the model for the full sample 1959:1-2006:1. We are interested in verifying that it fits the data reasonably well and, therefore, can be used to undertake the type of analysis we care about; and in examining whether the model's parameterizations can be simplified and certain specification choices matter for the results. Table 1 presents the posterior medians and standard deviations for i) a specification which employs the full set of parameters $(U R)$, ii) a specification which employs a separable utility function, $\omega_{2}=\omega_{5}=0$, and no reaction of the interest rate to real balances, $\lambda_{m}=0,\left(R_{1}\right)$, iii) a specification which assumes no reaction of interest rate to real balances, $\lambda_{m}=0,\left(R_{2}\right)$, and iv) a specification which employs a separable utility function, $\omega_{2}=\omega_{5}=0,\left(R_{3}\right)$.

A few aspects of the table deserve comments. First, priors and posteriors tend to have different locations, spreads and, in several cases, shape. Therefore, the sample appears to be informative about the properties of many of the parameters. Second, the mean estimate of $\omega_{2}$ and $\omega_{5}$ are positive and the posterior distribution is tight, both in an absolute sense and relative to the prior. The elasticity of the three arguments in the utility function, i.e. $\omega_{1}, \omega_{3}$ and $\omega_{4}$, have the expected signs.

Third, the parameters controlling the backward looking components of the Euler equation and the Phillips curve are small ( $h$ and $i_{p}$ ), smaller than those obtained, for example, by Smets and Wouters (2003), Primiceri and Justiniano (2008), or others. One reason for this is that the preliminary data transformation we use is different from theirs.

Fourth, the coefficients in the policy rule imply a relative mild smoothing desire and a somewhat more aggressive response to inflation and real balances. We experimented several versions of the monetary policy rule, where for instance interest rate were allowed to react to real balances (instead of real balances growth) or where the rection is contemporaneous rather than lagged. The fit of these specifications were poor and, in particular, the estimate 


\begin{tabular}{|c|c|c|c|c|c|c|c|}
\hline \multirow[b]{3}{*}{$\eta$} & \multirow[b]{3}{*}{ descr } & \multirow{2}{*}{\multicolumn{2}{|c|}{ Prior }} & UR & $R_{1}$ & $R_{2}$ & $R_{3}$ \\
\hline & & & & \multirow{2}{*}{\multicolumn{4}{|c|}{$\begin{array}{c}\text { Posterior } \\
\text { meadian }(\mathrm{sd})\end{array}$}} \\
\hline & & distr & mean $(\mathrm{sd})$ & & & & \\
\hline$h$ & habit in cons & $\operatorname{beta}(14,6)$ & $0.7(0.1)$ & $0.35(0.06)$ & $0.09(0.02)$ & $0.37(0.01)$ & $0.2(0.04)$ \\
\hline$\omega_{1}$ & $-U_{c} /\left(C * U_{c c}\right)$ & $\operatorname{gam}(4,0.25)$ & $1(0.5)$ & $0.87(0.11)$ & $1.66(0.16)$ & $0.07(0.02)$ & $1.58(0.11)$ \\
\hline$\omega_{2}$ & $\left(m * U_{c m}\right) /\left(U_{c c} C\right)$ & $\operatorname{gam}(4,0.25)$ & $1(0.5)$ & $0.58(0.08)$ & - & $1.46(0.05)$ & - \\
\hline$\omega_{3}$ & $-\left(l * V_{l l}\right) / V_{l}$ & $\operatorname{norm}(2,0.5)$ & $2(0.5)$ & $0.54(0.07)$ & $0.38(0.04)$ & $1.45(0.03)$ & $0.16(0.03)$ \\
\hline$\omega_{4}$ & $-\left(m * U_{m m}\right) / U_{m}$ & $\operatorname{gam}(4,0.25)$ & $1(0.5)$ & $0.09(0.05)$ & $3.76(0.20)$ & $0.12(0.01)$ & $0.81(0.07)$ \\
\hline$\omega_{5}$ & $U_{m c} C / U_{m}$ & $\operatorname{gam}(4,0.25)$ & $1(0.5)$ & $0.37(0.14)$ & - & $0.5(0.03)$ & - \\
\hline$a^{\prime} / a^{\prime \prime}$ & $k$ utiliz & $\operatorname{beta}(5.05,5.05)$ & $0.5(0.15)$ & $0.09(0.03)$ & $0.07(0.03)$ & $0.13(0.01)$ & $0.35(0.06)$ \\
\hline$S^{\prime \prime}$ & inv adj cost & $\operatorname{norm}(1,1)$ & $1(1)$ & $3.74(0.606)$ & $5.08(0.33)$ & $2.12(0.08)$ & $0.71(0.12)$ \\
\hline$\xi_{w}$ & wage stickiness & $\operatorname{beta}(12,12)$ & $0.5(0.1)$ & $0.15(0.02)$ & $0.04(0.01)$ & $0.34(0.01)$ & $0.21(0.01)$ \\
\hline$i_{w}$ & wage indexation & $\operatorname{beta}(1,1)$ & $0.5(0.3)$ & $0.46(0.25)$ & $0.13(0.11)$ & $0.64(0.03)$ & $0.63(0.07)$ \\
\hline$\epsilon_{w}$ & elast variety labor & $\operatorname{norm}(10,2)$ & $10(2)$ & $10(2.25)$ & $9.9(1.9)$ & $12.9(0.87)$ & $11.6(0.76)$ \\
\hline$\xi_{p}$ & price stickiness & $\operatorname{beta}(12,12)$ & $0.5(0.1)$ & $0.93(0.01)$ & $0.44(0.08)$ & $0.44(0.02)$ & $0.87(0.01)$ \\
\hline$i_{p}$ & price indexation & $\operatorname{beta}(1,1)$ & $0.5(0.3)$ & $0.04(0.05)$ & $0.08(0.09)$ & $0.08(0.01)$ & $0.01(0.01)$ \\
\hline$\epsilon_{p}$ & elast variety goods & $\operatorname{norm}(10,2)$ & $10(2)$ & $10.8(1.76)$ & $10.1(0.48)$ & $12.5(0.65)$ & $9.5(2.3)$ \\
\hline$\lambda_{r}$ & MP autoregressive & $\operatorname{beta}(10,2)$ & $0.8(0.1)$ & $0.79(0.04)$ & $0.8(0.04)$ & $0.92(0.02)$ & $0.8(0.04)$ \\
\hline$\lambda_{y}$ & MP resp to gdp & $\operatorname{norm}(0.15,0.05)$ & $0.15(0.05)$ & $0.13(0.01)$ & $0.12(0.011)$ & $0.14(0.01)$ & $0.14(0.01)$ \\
\hline$\lambda_{m}$ & MP resp to money & $\operatorname{norm}(0.3,1)$ & $0.3(1)$ & $2.91(0.12)$ & - & - & $2.9(0.31)$ \\
\hline$\lambda_{\pi}$ & MP resp to inflation & $\operatorname{norm}(2,1)$ & $2(1)$ & $6.48(0.44)$ & $6.42(0.62)$ & $5.04(0.01)$ & $5.27(0.31)$ \\
\hline$\rho_{e}$ & AR money demand & $\operatorname{beta}(2.62,2.62)$ & $0.5(0.2)$ & $0.95(0.01)$ & $0.98(0.01)$ & $0.98(0.02)$ & $0.97(0.01)$ \\
\hline$\rho_{b}$ & AR preference & $\operatorname{beta}(2.6,2.6)$ & $0.5(0.2)$ & $0.83(0.03)$ & $0.84(0.03)$ & $0.83(0.02)$ & $0.83(0.03)$ \\
\hline$\rho_{a}$ & AR technology & $\operatorname{beta}(2.6,2.6)$ & $0.5(0.2)$ & $0.98(0.01)$ & $0.94(0.01)$ & $0.86(0.02)$ & $0.80(0.03)$ \\
\hline$\rho_{i}$ & AR investment & $\operatorname{beta}(2.6,2.6)$ & $0.5(0.2)$ & $0.71(0.05)$ & $0.24(0.03)$ & $0.70(0.02)$ & $0.91(0.02)$ \\
\hline$\rho_{g}$ & AR government & $\operatorname{beta}(2.6,2.6)$ & $0.5(0.2)$ & $0.94(0.01)$ & $0.92(0.01)$ & $0.88(0.02)$ & $0.90(0.02)$ \\
\hline$\rho_{w}$ & AR wage markup & $\operatorname{beta}(2.6,2.6)$ & $0.5(0.2)$ & $0.96(0.01)$ & $0.96(0.01)$ & $0.92(0.002)$ & $0.76(0.03)$ \\
\hline$\rho_{p}$ & AR price markup & $\operatorname{beta}(2.6,2.6)$ & $0.5(0.2)$ & $0.87(0.03)$ & $0.92(0.01)$ & $0.97(0.001)$ & $0.78(0.024)$ \\
\hline$\sigma_{e}$ & SD money demand & $\operatorname{igam}(3,0.02)$ & $0.01(0.01)$ & $0.015(0.002)$ & $0.020(0.002)$ & $0.012(0.001)$ & $0.007(0.001)$ \\
\hline$\sigma_{b}$ & SD preference & $\operatorname{igam}(3,0.02)$ & $0.01(0.01)$ & $0.012(0.001)$ & $0.012(0.001)$ & $0.012(0.000)$ & $0.012(0.001)$ \\
\hline$\sigma_{a}$ & SD technology & $\operatorname{igam}(3,0.02)$ & $0.01(0.01)$ & $0.009(0.000)$ & $0.009(0.000)$ & $0.009(0.001)$ & $0.009(0.000)$ \\
\hline$\sigma_{i}$ & SD investment & $\operatorname{igam}(3,0.02)$ & $0.01(0.01)$ & $0.043(0.007)$ & $0.100(0.008)$ & $0.024(0.003)$ & $0.007(0.001)$ \\
\hline$\sigma_{g}$ & SD government & $\operatorname{igam}(3,0.02)$ & $0.01(0.01)$ & $0.034(0.002)$ & $0.034(0.002)$ & $0.033(0.001)$ & $0.034(0.002)$ \\
\hline$\sigma_{r}$ & SD monetary policy & $\operatorname{igam}(3,0.02)$ & $0.01(0.01)$ & $0.033(0.002)$ & $0.031(0.003)$ & $0.026(0.001)$ & $0.031(0.003)$ \\
\hline$\sigma_{w}$ & SD wage markup & $\operatorname{igam}(3,0.02)$ & $0.01(0.01)$ & $0.007(0.001)$ & $0.007(0.000)$ & $0.008(0.001)$ & $0.005(0.000)$ \\
\hline$\sigma_{p}$ & $\mathrm{SD}$ price markup & $\operatorname{igam}(3,0.02)$ & $0.01(0.01)$ & $0.034(0.006)$ & $0.016(0.001)$ & $0.016(0.001)$ & $0.030(0.003)$ \\
\hline$p$ & & & & & & & \\
\hline 0.1 & & & & -113.89 & -541.64 & -453.56 & -120.03 \\
\hline 0.3 & & & & -112.79 & -540.47 & -452.46 & -118.92 \\
\hline 0.5 & & & & -112.25 & -539.88 & -451.94 & -118.39 \\
\hline 0.7 & & & & -111.92 & -539.53 & -451.59 & -118.01 \\
\hline 0.9 & & & & -104.92 & -539.08 & -451.24 & -117.57 \\
\hline ar & & & & 32.05 & 33.93 & 49.33 & 40.55 \\
\hline
\end{tabular}

Table 1: Paramters description, priors, posteriors statistics, marginal likelihoods (ML) and acceptance rate (ar) for the four specifications. 
of the autoregressive coefficient of the Taylor rule was close to zero making monetary policy residuals highly serially autocorrelated. The rule we use has two importat features which turns out ot be important in estimation: it makes the relationship between interest rate and the right hand side variables dynamic; money growth enters the rule. To gain insights
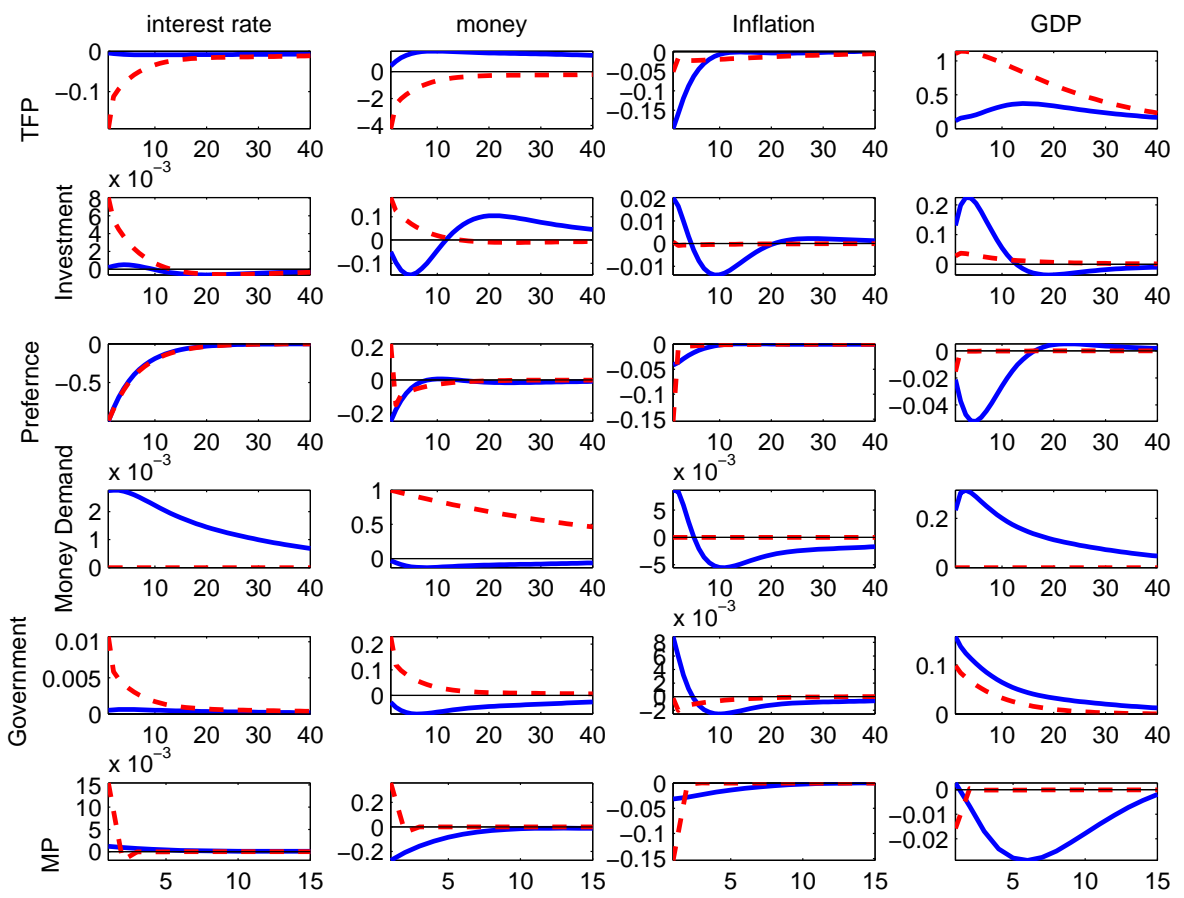

Figure 2: Impulse responses. Form top to bottom, TFP, Investment, Preference, Money Demand, Government, Monetary Policy. Solid (blue) line full model, dotted (red) line model with $\omega_{2}=\omega_{5}=\lambda_{m}=0$.

for the plausibility of the estimates, it is interesting to analyze the transmission mechanism of shocks and the decomposition of the variance implied by the full and restricted models. Figure 2 reports the responses of interest rate, inflation, real balances and GDP to impulse in supply (technology, investment) and demand (preference, money demand and government) shocks and monetary policy. The dynamics induced by supply shocks are in line with those of Semts and Wouters (2007), where for example following a positive TFP shock output increases while inflation and in the interest rate drop. An investment shock produces similar co-movements of the interest rate, the inflation and GDP and induces a drop in money demand. These dynamics are roughly similar in models where mony matters and model where money does not matter. The transmission of a monetary policy shock is instead different. In the basline model, a monetary policy tightening (positive monetary policy shock) increases the interest rate and makes M2 supply drop, generating a liquidity effect. 
As a results, the economy contracts, and output and inflation decrease. All the responses display some inertia and the response of GDP is quite sluggish.

When money does not matter, the correlation between interest rate and money conditional on monetary policy shocks is positive, implying that contractionary monetary policy generates a significant increase of the interest rate and of the money supply. Moreover, while money demand shocks have a non-negligible impact on nominal and real variables in the baseline model, in the restricted specification all these effetcs are forced to zero and are captured by other shocks.

\begin{tabular}{|c|c|c|c|c|c|c|c|c|c|c|c|c|}
\hline \multirow[b]{2}{*}{$k$-step ahead } & \multicolumn{3}{|c|}{ UR } & \multicolumn{3}{|c|}{$\omega_{2}=\omega_{5}=\lambda_{m}=0$} & \multicolumn{3}{|c|}{$\lambda_{m}=0$} & \multicolumn{3}{|c|}{$\omega_{2}=\omega_{5}=0$} \\
\hline & 8 & 16 & 40 & 8 & 16 & 40 & 8 & 16 & 40 & 8 & 16 & 40 \\
\hline & \multicolumn{12}{|c|}{ GDP } \\
\hline Money Shock & 24.7 & 14.9 & 11.1 & 0.0 & 0.0 & 0.0 & 0.0 & 0.0 & 0.0 & 0.1 & 14.2 & 0.7 \\
\hline Preference & 0.6 & 0.0 & 0.0 & 0.0 & 0.0 & 0.0 & 0.0 & 0.1 & 0.0 & 0.0 & 1.1 & 0.0 \\
\hline Technology & 21.9 & 61.2 & 82.2 & 59.4 & 58.9 & 48.3 & 19.5 & 3.2 & 0.0 & 20.1 & 0.6 & 3.7 \\
\hline Investment & 17.1 & 1.9 & 1.5 & 0.3 & 0.1 & 0.0 & 3.4 & 3.9 & 0.1 & 50.2 & 57.4 & 90.0 \\
\hline Government & 6.3 & 3.0 & 1.8 & 0.4 & 0.1 & 0.0 & 0.0 & 0.0 & 0.0 & 1.3 & 21.3 & 0.8 \\
\hline Monetary Policy & 0.6 & 0.0 & 0.0 & 0.0 & 0.0 & 0.0 & 0.0 & 0.0 & 0.0 & 0.0 & 2.2 & 0.1 \\
\hline Wage Markup & 5.1 & 11.2 & 0.4 & 14.3 & 19.3 & 41.7 & 17.7 & 8.6 & 0.8 & 10.5 & 1.2 & 1.5 \\
\hline \multirow[t]{2}{*}{ Price Markup } & 23.6 & 7.8 & 3.0 & 25.6 & 21.5 & 10.0 & 59.4 & 84.2 & 99.1 & 17.7 & 1.9 & 3.3 \\
\hline & \multicolumn{12}{|c|}{ Inflation } \\
\hline Money Shock & 2.3 & 15.2 & 11.0 & 0.0 & 0.0 & 0.0 & 0.0 & 0.0 & 0.0 & 18.0 & 46.4 & 72.5 \\
\hline Preference & 2.8 & 0.4 & 0.2 & 0.7 & 0.1 & 0.0 & 7.4 & 0.5 & 0.0 & 0.0 & 0.0 & 0.0 \\
\hline Technology & 22.2 & 0.5 & 7.8 & 59.7 & 59.2 & 48.9 & 18.4 & 3.3 & 0.0 & 15.5 & 1.5 & 1.5 \\
\hline Investment & 51.7 & 66.4 & 16.6 & 0.3 & 0.1 & 0.0 & 3.1 & 3.9 & 0.1 & 48.3 & 50.5 & 24.0 \\
\hline Government & 1.3 & 6.0 & 3.3 & 0.3 & 0.1 & 0.0 & 0.0 & 0.0 & 0.0 & 0.6 & 0.5 & 0.1 \\
\hline Monetary Policy & 6.2 & 0.4 & 0.5 & 0.0 & 0.0 & 0.0 & 0.0 & 0.0 & 0.0 & 0.0 & 0.1 & 0.0 \\
\hline Wage Markup & 0.2 & 10.1 & 32.4 & 14.4 & 19.4 & 40.6 & 16.6 & 8.8 & 0.9 & 11.4 & 0.5 & 0.6 \\
\hline Price Markup & 13.3 & 1.1 & 28.2 & 24.6 & 21.1 & 10.5 & 54.5 & 83.5 & 99.0 & 6.1 & 0.5 & 1.3 \\
\hline
\end{tabular}

Table 2: $k$-step ahead forecast error for GDP and Inflation

Table 2 presents the $k$-step ahead forecast error for GDP and inflation in terms of structural shocks. The table contains several results. First, while in the unrestricted specification the money demand shock contributes significantly to the volatility of GDP and inflation at horizons from 2 until 10 years, in the restricted specifications money demand shocks play a negligible role. In particular, they do not contribute to explain GDP forecast error at any horizons, and they explain a small portion of the volatility of inflation as long as $\lambda_{m} \neq 0$. Second, while markup shocks have some role in explain GDP volatility at short horizons, their impact tend to disappear in the long run, and supply shocks, i.e. technology shocks, appear to be the predominant source of GDP fluctuations. In line with Smets and 
Wouter (2007), in the most restricted specification $\omega_{2}=\omega_{5}=\lambda_{m}=0$ wage markup shocks counterintuively explain a large portion of the volatility of GDP at business cycles frequencies. In sum, the dynamics described by the unrestricted and the restricted specifications differ substantially, in particular as far as the transmission of monetary policy shocks and the share of the variance of output and inflation attributed to shocks. Given the focus of the investigation, models where money is not allowed to matter seem unable to capture the main features of the data.

It is also instructive to inspect the time path of the estimated residuals to check for interesting pattern left unexplained in the estimation. Figure 3 plots the smoothed residuals obtained with the unrestricted specification. It is clear that during the 1970's, the US economy experienced a series of negative monetary policy shocks while at the beginning of the 80 's monetary policy is characterized by a series of positive shocks. Thus the path of
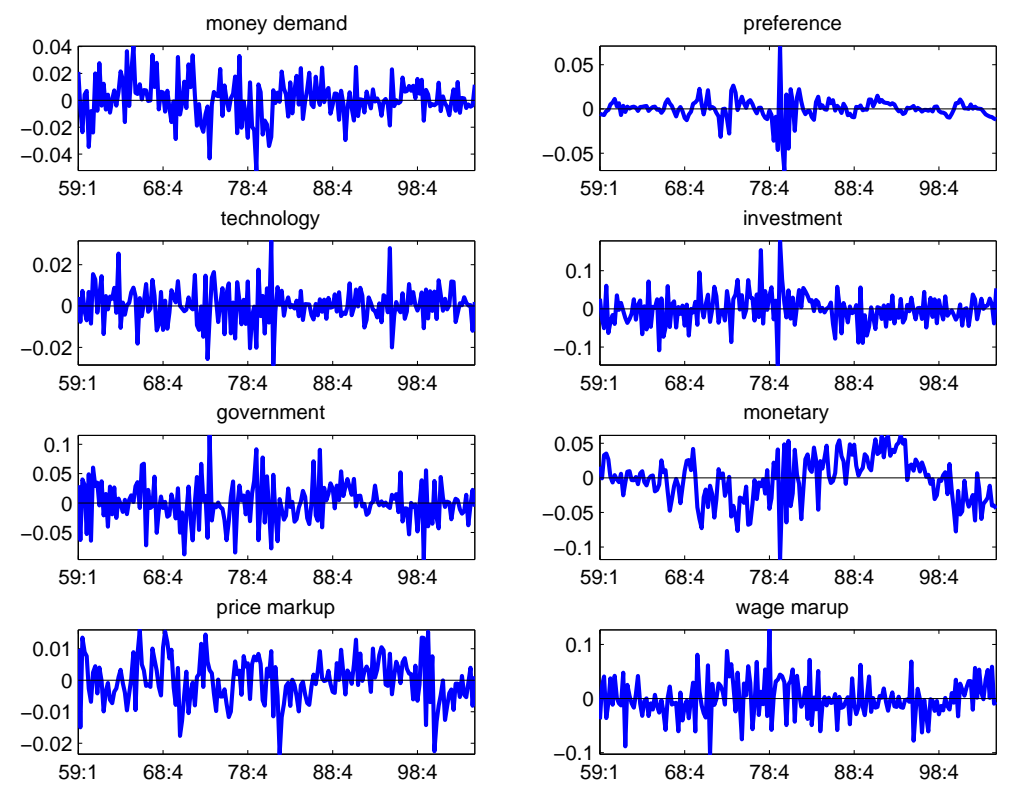

Figure 3: Residuals for the unrestricted specification. From top left, money demand, preference, technology, investment, government, monetary, price markup, wage markup.

policy shock implies that monetary policy was accommodative for most of the 1970s and became much tighter later on. Interestingly, the model also predicts a sequence of negative interest shocks just after 2001. While the monetary policy residuals in the restricted specifications are similar, see figure 4 , the implied path displays a more pronounced autoregressive component and residuals tend to be asymmetric and skewed towards negative values.

Table 1 which reports the marginal likelihood of each model confirms previous conclu- 

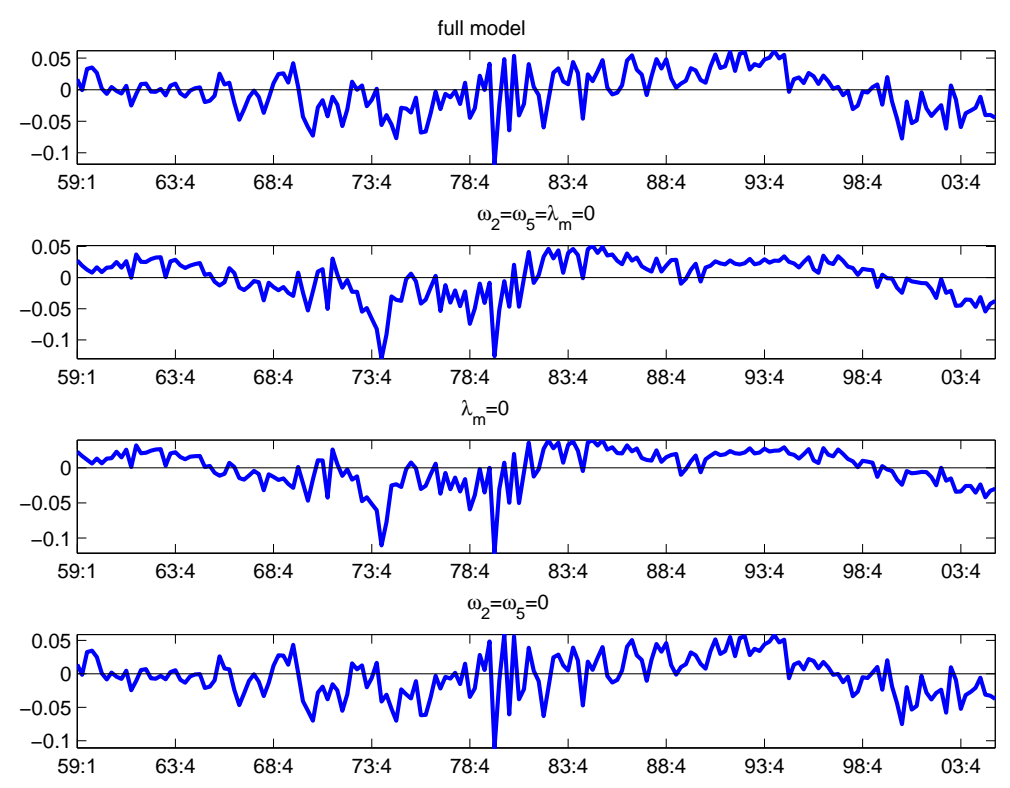

Figure 4: Monetary Policy residuals across specifications.

sions. For a wide range of $p$-values, the unrestricted specification is superior to all other structural alternatives we considered. Thus allowing real balances to play a role and specifying a policy rule which depends, among other things, on the growth rate of nominal balances gives an important advantage in terms of model's fit and properties of the residuals. Hopefully, this superiority will also help in providing a better economic interpretation of the evidence.

\section{Inflation dynamics}

There is substantial controversy in the literature regarding the role that monetary policy had in shaping the dynamics of US inflation over the last forty years. Conditional on the model, we can shed some light on the issue by analyzing the time profile of the estimated autocovariance function of inflation, by measuring the contribution of policy shocks to the changes, and by interpreting the evolution of these statistics in terms of changes in the parameters of the model.

Roberts (2006) and Cecchetti et al. (2007) have studied, by way of stochastic simulations and/or standard sensitivity analysis, how changes in the parameters of a small scale model where money plays no role affect inflation variability and persistence. Both consider a somewhat hybrid model, where the Euler equation is ad-hoc, a time varying inflation target enters the policy rule and the policy shock is persistent. Roberts finds that changes in 
the policy parameters can account for the fall in the variance of inflation but not on its persistence. Cecchetti et al. find that two parameters are crucial: the degree of indexation in the Phillips curve and the variance of the policy shocks. In particular, only a considerable fall in the indexation parameter is capable of explaining the absolute fall in persistence that researchers have documented. In addition, when indexation is low, a fall in the variance of the policy shocks may also decrease inflation persistence.

The analysis we conduct has two main differences with these papers. First, contrary to these authors, we examine the contribution of monetary policy shocks to the evolution of the variability and persistence of inflation, (much in the same spirit as Gambetti et al. (2008) but using a structural model rather than a VAR) and examine how the evolution of certain parameter estimates changed the contribution of monetary policy shocks. To do this, let $x_{t}=\left[x_{1 t}, x_{2 t}\right]^{\prime}$ and represent the solution of the model as $x_{t+1}=W_{1}(\eta) x_{t}+W_{2}(\eta) \zeta_{t+1}$. Then $\operatorname{var}\left(x_{t}\right)=\Sigma_{x}$ solves $\Sigma_{x}=W_{1}(\eta) \Sigma_{x} W_{1}(\eta)^{\prime}+W_{2}(\eta) \Sigma_{\zeta} W_{2}(\eta)^{\prime}$ and $\operatorname{ACF}(1)\left(x_{t}\right)=W_{1}(\eta) \Sigma_{x}$, where $\Sigma_{\zeta}$ is the covariance matrix of the shocks and $\mathrm{ACF}(1)$ the first autocovariance coefficient. Since monetary shocks are uncorrelated with the other disturbances, the contribution of monetary shocks to these statistics can be computed by replacing $\Sigma_{\zeta}$ with a matrix which is zero everywhere except in the diagonal position corresponding to the monetary shocks. As estimates of $\eta$ change over time, we can assess how the contribution of monetary shocks to these statistics has changed and attribute the variations to particular parameters.

Second, while one would be tempted to present a graph showing how inflation dynamics change when $\eta$ varies within a reasonable range, keeping all the other parameters fixed at some value (for example, those estimated in the first column of table 1), one should be aware that such a graph would be meaningless in our context, since the correlation structure of estimates implies that the effect of changes in some parameters can not be measured independently of the others. To address the questions of interest we have instead estimated a version of the model where some parameters are fixed on many overlapping samples. We started from the sample [1959:1, 1976:1] and repeated estimation moving the starting date by two year, while keeping the size of the sample constant to 17 years. Keeping a fixed window size is necessary to eliminate differences produced by different precision of the estimates. The last subsample is [1989:1-2006:1], so that we produce 16 posterior distributions for the parameters. Since the final sample roughly corresponds to Greenspan's tenure, we can compare the estimated stance of monetary policy in the 1990's, where inflation was low, with the one of the 1970's, where inflation was high.

Given the large number of parameters involved (39) and the sample length (65), we have decided to reduce the number of parameters to estimate and focus on those which are of 
interest. Thus, in each estimation window, we keep fixed the time discount factor $\beta=0.995$, the capital depreciation rate $\delta=0.025$, the steady state government spending over GDP $\epsilon^{g}=0.18$, the capital share $\alpha=0.3$, the steady state inflation $\pi=1.006$. Moreover, we set the two elasticities in the labor and intermediate good markets to 13 . The remaining parameters are estimated.

\subsection{The volatility and the persistence of inflation}

It is well documented in the literature that the times series properties of US inflation have changed over time (see e.g. Stock and Watson (2002)). Is the model able to capture these facts? What is the contribution of policy shocks to these changes? Figure 5 presents statistics recursevely computed from the data, the estimates of these statistics obtained in the model and the statistics produced if only one type of shocks - technology shocks (TFP and investment), monetary policy shocks (money demand shocks are not reported here since are not important) and real demand shocks (government spending and preference)- were present. We measure volatility in the model using the population unconditional variance and persistence using the population first order autocorrelation coefficient obtained using the solution of the model and posterior mean estimates of the parameters in each sample.

The statistics in the data show important time variations: for example, there is a large drop in volatility when the samples exclude the early 1970s, while the fall persistence is evident only if windows including the 1980 and the 1990s are considered. Interestingly, after that inflation persistence starts rising again. While the model is able to track quite well the volatility dynamics, it fails to capture the drop in persistence experienced in the sample including the 80s and 90s. Notice however, the fall in inflation persistence is neither smooth nor long-lived and the same pattern is maintained if the windows change in size of if the sample is split in less overlapping windows.

The changes in volatility and presistence could be due to different causes. Interestingly, monetary policy shocks seem to have a role in shaping the dynamics of inflation volatility and appear to be responsible in part for the decrease observed in the latest samples. Moreover, they track pretty well the rise and fall of volatility over time. However, other shocks appear to be responsible for the evolution of the autocovariance function of inflation. Technology shocks, for example, affect inflation volatility and persistence mainly at the beginning of the sample and their importance is falling over time. Oil shocks which materialized at the end of the 70s are captured here as negative supply shocks, and contribute to the inflation volatility at the beginning of the sample. Real demand shocks matter also for the dynamics of inflation volatility and persistence. However, their role is quite modest. 

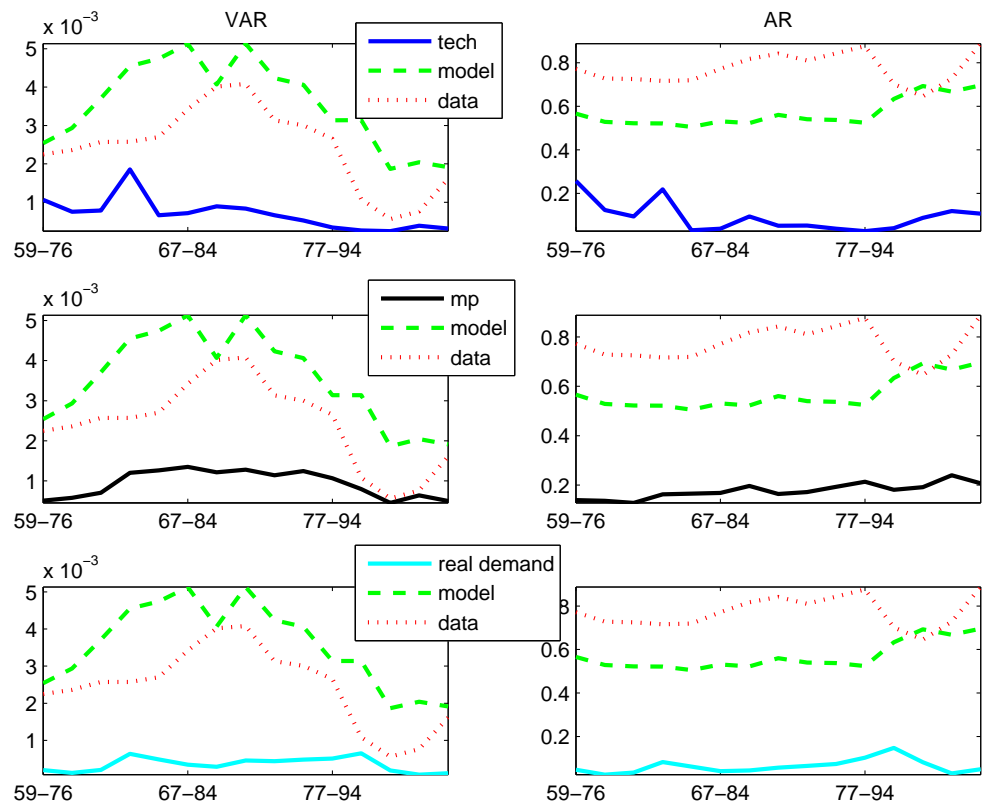

Figure 5: Variance (left) and persistence (right) of Inflation. Dotted line data, dashed line full model, solid line model only with technology shocks (TFP and investment) first row, monetary policy shocks second row and real demand shocks (preference and government) las row.

\subsection{The transmission of monetary policy shocks}

It is interesting to examine how the variations observed in figure 5 decompose into variations in the transmission of policy shocks over time (for a given variance of the shocks) and variations in the volatility of policy shocks. Gambetti et. al. (2008) have shown, in the context of a SVAR with time varying coefficients, that there are variations in the size and the shape of the responses to monetary shocks and in the variances of these shocks. What does our structural analysis tell us about this issue? Figure 6 presents the responses to a normalized monetary policy shock in the 16 samples we have considered. Hence, the variations it displays only reflect changes in the structural parameters of the model and not changes in the variance of the policy shocks (these will be analyzed later on).

Overall, the shape of the responses to policy shock has not changed much over time: when monetary policy is tight, inflation and output fall. Quantitatively, the impact effect of monetary shocks is somewhat reduced over time.

One other features of the responses deserve some comment: the largest responses are all instantaneous. This may appear surprising relative to the conventional VAR wisdom. One should stress that much of the conventional wisdom is derived using restrictions which are 

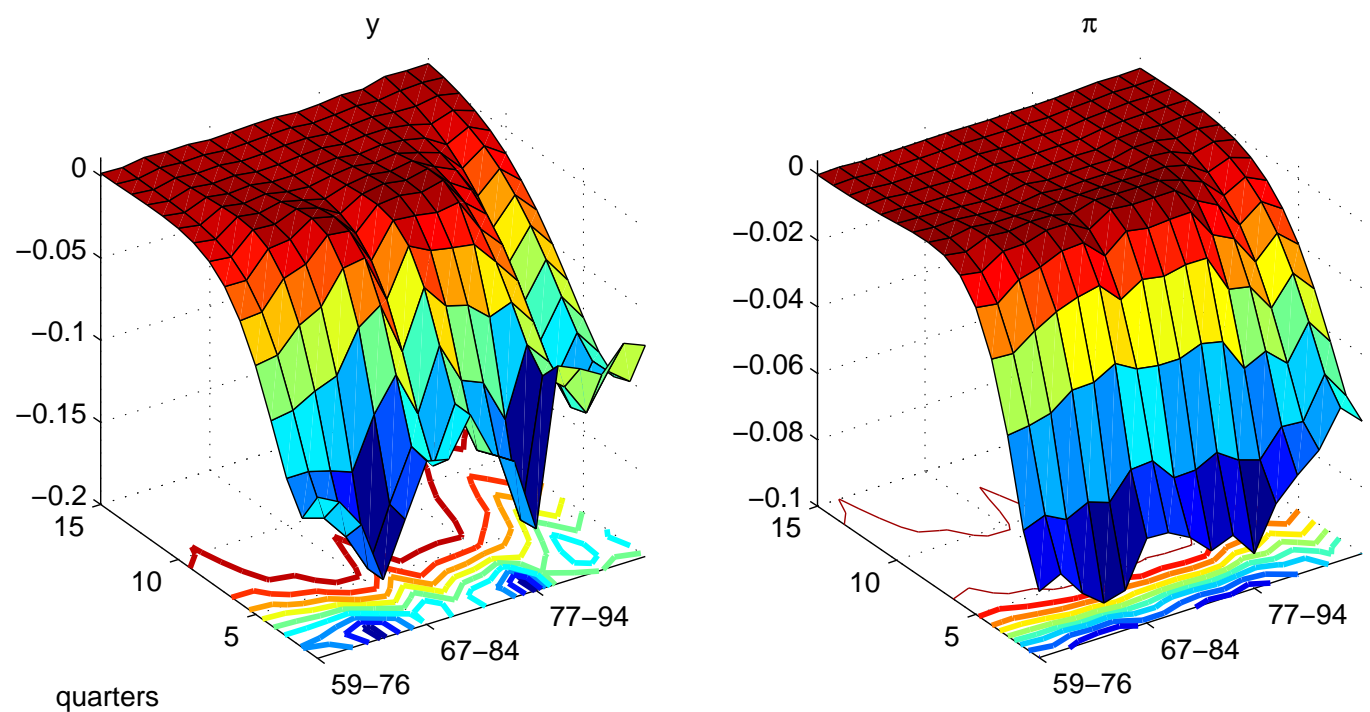

Figure 6: Impulse response of output and inflation to a positive monetary shocks.

inconsistent with the theory embedded in models like the one we use and that when the restrictions that theory imposes are used, no strong delayed response typically appears (see Canova and De Nicolo' (2002)). Nevertheless, it is important to note that large delayed effects in the responses to monetary shocks are possible only if the model features interesting higher order dynamics. Because the price indexation parameter and the habit parameter are estimated to be relatively small, and no other artificial delays are introduced, the conditional dynamics of our model are similar to those of a $\operatorname{VAR}(1)$.

\subsection{The rise and fall in the level of inflation}

One crucial event we would like our model to explain is the rise in the level of inflation in the 1970s and the subsequent fall in the 1980s. The conventional wisdom attributes these ups and downs to a changing monetary stance, which was lax in the 1970s and became tight in the 1980s. The analysis of the previous subsections is inconclusive since the statistics we report are not designed to shed light on this issue. Here we present the results of a historical decomposition exercise where we take mean posterior estimates of the parameters in four samples (1961-1978, 1965-1982, 1967-1984, 1969-1986), project the implied path of inflation out-of-sample, and ask whether and by how much policy shocks account for the deviation 


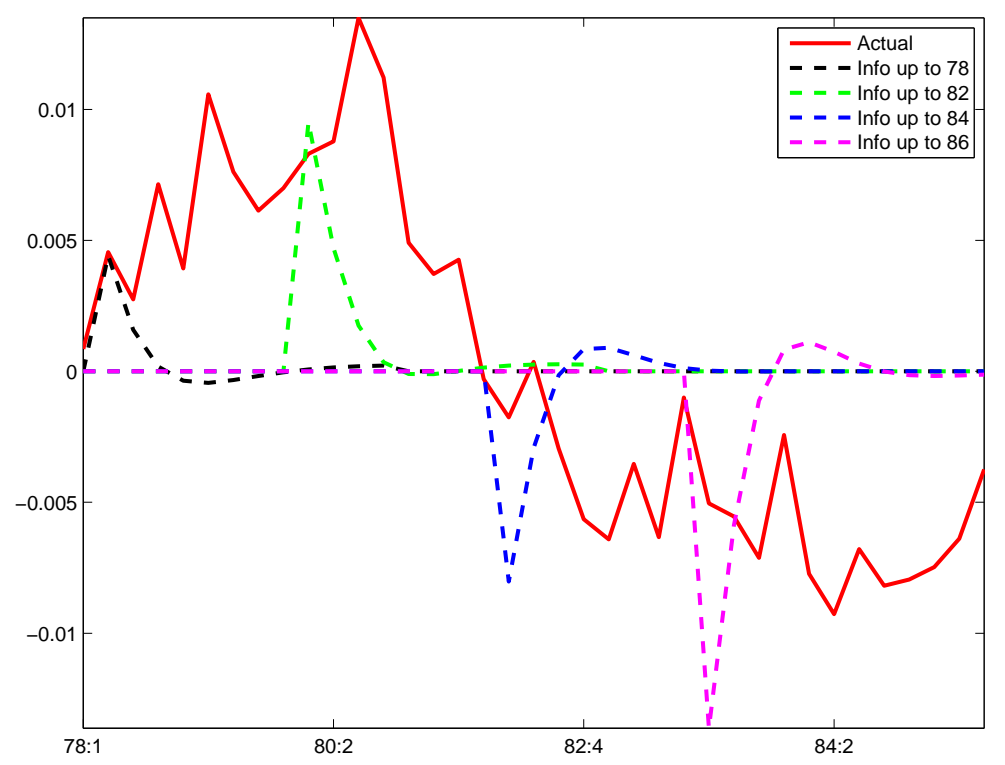

Figure 7: The rise and fall of inflation

between the actual and the projected path. Formally, we decompose inflation in terms of realized monetary policy shocks,

$$
\tilde{\pi}_{T}=S A_{3}\left(\bar{\eta}_{T}\right)\left(\sum_{m=1}^{T}\left[A_{1}\left(\bar{\eta}_{T}\right)\right]^{T-m} A_{2}\left(\bar{\eta}_{T}\right) \hat{\zeta}_{m}^{\dagger}\right)
$$

where $S$ is a selection matrix that picks inflation out of the vector of observable variables, $\bar{\eta}_{T}$ is the mean posterior estimate using the information up to $T .\left\{\hat{\zeta}_{m}^{r}\right\}_{m=1}^{T}$ is the set of realized monetary policy shocks in the sample considered and $\hat{\zeta}_{m}^{\dagger}=\left[0,0,0,0,0, \hat{\zeta}_{m}^{r}, 0,0\right]$. Then, we project inflation out of sample conditional on time $T$ information,

$$
\tilde{\pi}_{T+k}^{e}=E_{T}\left(\tilde{\pi}_{T+k}\right)=S A_{3}\left(\bar{\eta}_{T}\right)\left[A_{1}\left(\bar{\eta}_{T}\right)\right]^{k}\left(\sum_{m=1}^{T}\left[A_{1}\left(\bar{\eta}_{T}\right)\right]^{T-m} A_{2}\left(\bar{\eta}_{T}\right) \tilde{\zeta}_{m}^{\dagger}\right)
$$

Figure 7, which presents the actual (demeaned) and the counterfactual inflation paths, displays interesting aspects. The sequence of policy shocks that materialized after 1978:1 would have implied an increase in the level of inflation, given the parameter estimates we obtain. Hence, monetary policy was rather accommodative in these periods. This pattern seems to change after 1982:1. The sequence of policy shocks that materialized after that date would have implied a considerable decline in the level of inflation, given parameter estimates. Hence, monetary policy had become quite restrictive after this date and, if only policy shocks would have been present, inflation would have been very low during the 
following 3 years, when information up to 1984:4 is used. Thus, policy shocks quantitatively predict movements in the actual level of inflation, and can account for the direction of the changes over the periods we consider.

How does one reconcile the evidence of figures 5 and 7? Figure 5 was concerned with the in-sample explanatory power of policy shocks for volatility and persistence. Figure 7 is instead concerned with the out-of-sample explanatory power of these shocks for the level of inflation in the next three years. Therefore, the fact that these shocks may have some room in explaining changes in the autocovariance function of inflation does not imply the fact that policy shocks are important to explain changes in the level of inflation.

\subsection{Bringing the shocks of the 70s in the Greenspan era}

What would have happened to inflation if we could bring the shocks of the 70s during the 'Great Moderation' era? Would we still observe a flat and low volatile pattern of inflation? Usually, counterfactuals on monetary policy are performed by moving the monetary policy of Alan Greenspan during the oil crisis, which means asking whether the sole monetary policy would have been able to stabilize the economy given the intense shocks and the economic structure of the 70s. Here, we take a different stand and ask less to monetary policy. We would like to know whether the entire structure of the US economy, private and public sectors as a hole, would be able to absorb and mitigate the realized innovations of the $70 \mathrm{~s}$.

More precisely, we compute the realized innovations of the sample that goes from 1967q1 to $1984 \mathrm{q} 1$ from $\widehat{\zeta}_{t+1}^{70}=W_{2}^{-1}\left(\eta^{70}\right)\left(x_{t+1}-W_{1}\left(\eta^{70}\right) x_{t}\right)$, where $\eta^{70}$ is the mean of the posterior distribution of the sample $[1967 q 1-1984 q 1]$. We then simulate implied paths for inflation assuming that the economy evolves according to the estimated structure during the 90s and it is feeded with the shocks of the 70s, i.e. $x_{t+1}^{s}=W_{1}\left(\eta^{90}\right) x_{t}^{s}+W_{2}\left(\eta^{90}\right) \widehat{\zeta}_{t+1}^{70}$ where $\eta^{90}$ is the mean of the posterior distribution of the sample $[1987 q 1-2006 q 1]$. We simulate data under three assumption about the monetary policy residuals: (a) a totally passive monetary policy intervention, i.e. monetary policy residuals set to zero, (b) the 70s monetary policy intervention, i.e. monetary policy residuals of the 70s, (c) the Greenspan monetary policy intervention, i.e. monetary policy residuals of the $90 \mathrm{~s}$.

Figure 8 plots the impled paths under the three different assumptions and the actual path of inflation during the 'Great Moderation' period. The figure suggests that regardless on the assumption about the monetary policy residuals the implied paths for inflation display fluctuations considerably more volatile and persistent than actual ones of the 90 's. This means that neither the monetary policy of Alan Greenspan neither the economic 


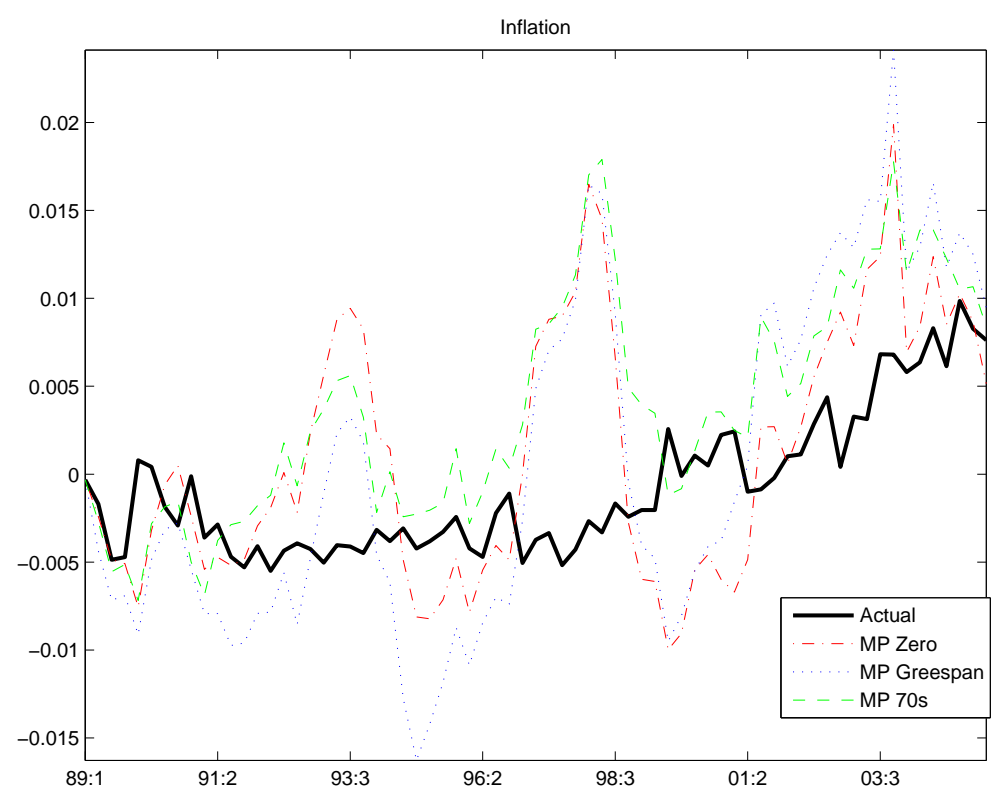

Figure 8: Implied paths of inflation with the shocks of the 70's.

structure of the 90 's would be able to cope with the deep shocks of the 70's. This result provides additional evidence that the sources of great moderation arise from differences in the intensity of the shocks rather than policy actions. However, it is important to stress that we do not use (and know) the monetary policy interventions (residuals) that Alan Greenspan would have done if he knew that he was facing the the shocks of the 70's (i.e. the distribution of the structural shocks of the 70's). While it would be the correct set of monetary policy residuals to work with, it is impossible to carve them out from the data.

\subsection{Summary}

The analysis of this section has shown that the model captures the time profile of inflation volatility quite well and attributes part of the changes to monetary policy shocks. Nevertheless, policy shocks do not have a predominant role in the decline: in fact, the transmission of policy disturbances is broadly unchanged over time. Hence, changes in the structural parameters somewhat average out and do not amplify changes in the variance of the monetary shocks. On the other hand, the rise and fall in the level of inflation appears to be linked to the sign and, to some extent, the magnitude of realized policy shocks. Absent these shocks the ups and downs of inflation would have been much smaller. Finally, the 'Great Moderation' episode seems to be more likely linked with the intensity of the shocks rather then changes in the monetary policy behavior. Overall, the evidence suggests that changes in the transmission of shocks other than policy disturbances are as or more impor- 
tant in explaining the changes in the autocovariance function of inflation. To understand what factors may have given these shocks an important role, we next turn to examine the parameter estimates we obtain in different samples.

\section{$5 \quad$ Rolling parameter estimates}

Figure 9 presents the evolution of the posterior mean of interesting (functions of the) parameters over different samples. For the sake of readability, we omit posterior credible sets - since they are relatively tight, the variations we present are typically a-posteriori significant - and report results for all the 16 rolling samples we have considered. Consistent with

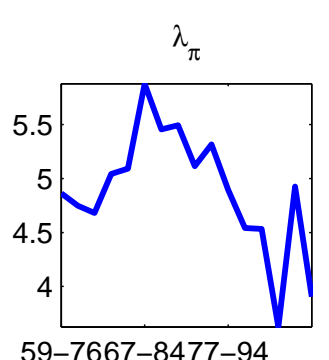

59-7667-8477-94

$\omega_{2} / \omega_{1}$

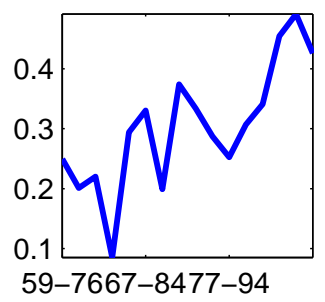

$\sigma_{e}$

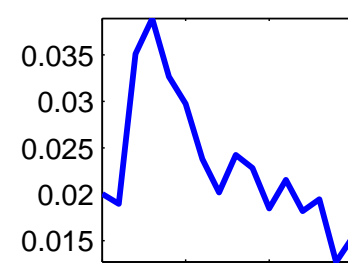

59-7667-8477-94

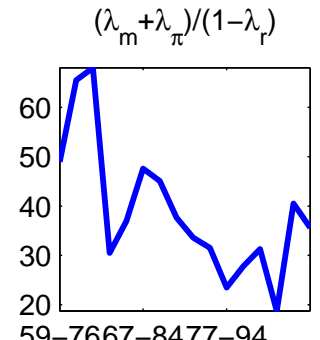

59-7667-8477-94

$\omega_{1}$

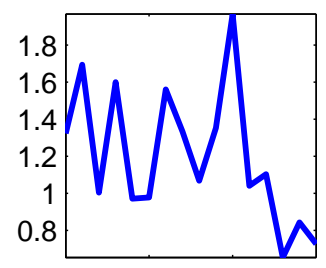

59-7667-8477-94

$\sigma_{\mathrm{b}}$

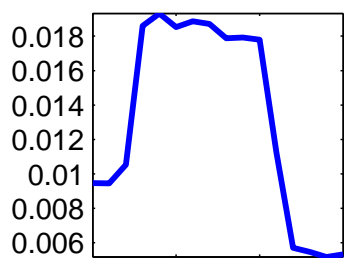

59-7667-8477-94
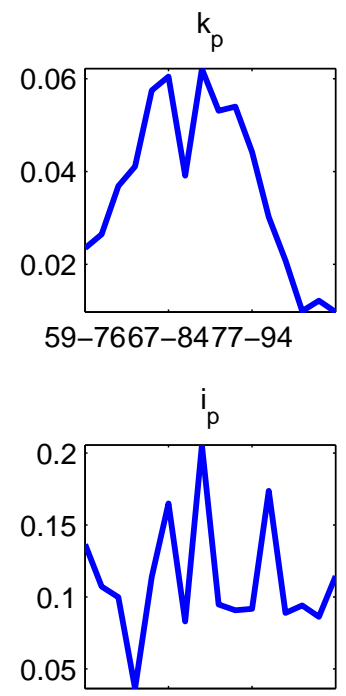

59-7667-8477-94

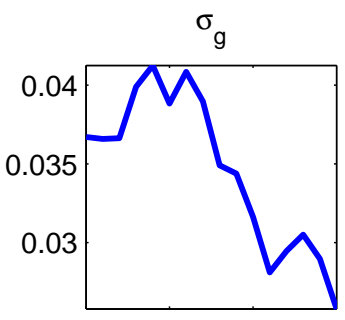

59-7667-8477-94

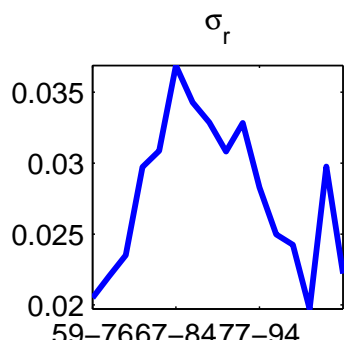

59-7667-8477-94

Figure 9: Rolling parameter estimates.

the analysis of Clarida et al. (2000), the figure shows that short run policy coefficient on inflation increases in the samples which mainly include the 1980s. Interestingly, and consistent with the structural VAR evidence of Canova and Gambetti (2009), the posterior mean estimate falls somewhat in the latest samples. Hence, while Greenspan was tougher than 
Burns in fighting inflation, the posterior distributions which include only the 1990s and the beginning of the 2000s show a reduced short run concern for inflation. This contrasts with the dynamics displayed by the long run coefficient on nominal variables (computed as $\left.\left(1-\lambda_{r}\right)^{-1}\left(\lambda_{\pi}+\lambda_{m}\right)\right)$. Here a clear decreasing pattern emerges with a peak located in the beginning of the sample. Note that the coefficient on the output (not shown here) is stable over time and shows no sign of increase in correspondence to the drop in the long run coefficient of nominal aggregates.

The posterior mean of the standard deviation of the policy shock shows some variations over time. As convectional wisdom suggests there is a decrease (to 0.035 from 0.025 ) in the samples from (1959-1976) to (1969-1986) but this decrease is reversed in the next few samples. This evidence is a bit surprising, but it is in line with the evidence produced by the Markov switching approach of Sims and Zha (2006), and the recursive analysis of Gambetti et al. (2008). It is worth mentioning that decreasing the length of the windows does not change this pattern: the increase present in the last few years of the sample is consistent with the more active role that the Fed has taken since 2001.

There are changes also in the posterior mean of other important parameters. For example, there are shifts in responsiveness of the output to real balances (see the real balance trade-off, $\omega_{2} / \omega_{1}$ ) and in the responsiveness of inflation to the marginal cost (Phillips curve trade-off). The fact that the real balance tradeoff is increasing, coupled with a volatile but overall constant Phillips curve tradeoff, indicates that real balances may have played different roles at different points in time. For example it is possible that real balances behaved as close proxies of consumer purchasing power in the early samples while they proxy for segmented asset markets in later samples (see e.g. Alvarez and Lippi, (2009)).

Interestingly, many other standard deviations display significant time variations. For instance, the standard deviations of government spending, preference and money demand shocks increased at the beginning of the samples, and then steadily decreased, giving support to the idea that many structural shocks have been less intense in the latter part of the sample, see e.g. Gali and Gambetti (2009).

In sum, the parameter changes we describe can explain why shocks other than monetary policy disturbances have an important role in explaining the variations in the volatility of inflation documented in figure 5 . It is because output changes in response to these shocks are larger, because changes in output are proportionally more important to explain inflation changes (and because the size of these shocks fell) that we see a large decline in the volatility of inflation over time. 


\section{Conclusions}

This paper examines the contribution of policy shocks to the dynamics of inflation using a medium scale structural model estimated with US post-WWII data and Bayesian techniques over rolling samples. The model belongs to the class of New-Keynesian structures that have been extensively used in the literature but explicitly allows money to play a role. Bayesian techniques are preferable to standard likelihood methods or to indirect inference (impulse response matching) exercises, because the model we consider is a false description of the DGP of the data and misspecification may be important. We show that our approach delivers interesting estimates of the structural parameters when priors are broadly noninformative and the policy reaction function appropriately chosen. We also demonstrate that the model fits the data reasonably well and that alternative structural specifications produce lower marginal likelihoods and fail to capture important aspects of the data.

Our model captures the fall in inflation volatility and attributes a portion of the changes to monetary policy shocks. We detect level but not shape differences in the transmission of policy shocks which tend to make inflation and real balances somewhat less reactive to policy disturbances as time went by. Finally, variations in the level of inflation are qualitatively related to policy shocks: had those been absent, the rise of the 1970s and the fall of 1980s would have been much more modest.

A number of structural changes drive these results. We find support for the conjecture that the Fed had a much stronger short run "dislike" for inflation in later samples but also notice that the long run coefficient on nominal variables has been steadily decreasing. In agreement with the good luck hypothesis, we detect variations in the posterior mean estimate of the variance of the policy shocks. Nevertheless, the variations we discover are typically reversed over time. Perhaps surprisingly, we find that these variations do not change very much the way monetary shocks are transmitted to the economy.

In sum, a combination of causes is responsible for the changes in the level and the autocovariance function of US inflation over the last forty years: changes in the variance of the shocks, in the parameters regulating the private sector and in the policy rule all more or less contributed to explain why inflation rose and fell and why inflation variability subsided. These conclusions are rather different than those present in the literature, with the exception of Gambetti et. al. (2008).

There are a number of ways our analysis can be extended. For example, the estimation approach we employ treats expectations as latent variables. However, measures of output and inflation expectations, do exist in the literature. While these proxies are probably 
contaminated by measurement error, it would be interesting to see whether they provide additional or contrasting information about the issues at stake. Similarly, it is important to consider additional statistics to the evaluation process: while the model seems by and large well misspecified, it may not capture the time profile of the dynamics of a particular variable well. Finally, the use of alternative rolling estimation techniques, such as those employed by Kapetanios and Yates (2008), can help us to understand whether the conclusions are robust also along this dimension. We leave all these extensions for future research. 


\section{References}

Alvarez, F. and F. Lippi (2009), "Financial Innovation and the Transactions Demand for Cash", Econometrica, 2009, 77(2), pp. 363-402.

Bernanke, B. and I. Mihov (1998), "Measuring monetary policy", The Quarterly Journal of Economics, 113, 869-902.

Boivin, J. and M. Giannoni (2006), "Has monetary policy become more effective?", Review of Economics and Statistics, 88, 445-462.

Campbell, J. and Herkovitz, Z. (2006), "The Role of collateralized household debt in macroeconomic stabilization", Federal Reserve Bank of Chicago, manuscript.

Canova, F. and De Nicolo, G. (2002), "Money Matters for Business Cycle Fluctuations in the G7", Journal of Monetary Economics, 49, 1131-1159.

Canova, F. and Gambetti, L. (2009), "Structural Changes in the US Economy: Is There a Role for Monetary Policy?", Journal of Economic Dynamics and Control. 33(2), 477-490.

Canova, F. and Gambetti, L. (2007), "Do inflation expectations matter? The Great Moderation revisited", available at www.econ.upf.edu/crei/people/canova.

Cecchetti, S., Hooper, P., Kasman, B., Schoenholtz, K. and Watson, M. (2007) Understanding the evolving inflation process, Forum report 1, Rosenberg Institute For Global Finance, Brandeis University.

Chang, Y., Doh, T. and Schorfheide, F. (2006) "Non-stationary hours in a DSGE model", Journal of Money, Credit and Banking, 39(6), 1357-1373.

Clarida, R., J. Gali and M. Gertler (2000), "Monetary policy rule and macroeconomic stability: evidence and some theory", Quarterly Journal of Economics, CXV, 147-180.

Del Negro, M. and Schorfheide, F. (2004), "Priors from general equilibrium models for VARs", International Economic Review, 45, 643-673.

Gali, J and Gambetti, L. (2009), "On the sources of Great Moderation", American Economic Journal: Macroeconomics, 1(1), 26-57.

Gambetti, L. Pappa, E. and Canova, F. (2008), "The structural dynamics of US output and inflation. What explains the changes?", Journal of Money Credit and Banking, 40(2), 369-388.

Fernandez Villaverde, J. and Rubio Ramirez, J. (2008), "How structural are structural parameter values", 2007 NBER Macroeconomic Annual, 83-137.

Geweke, J. (1998), "Using simulation methods for Bayesian econometric models: inference, development and communication", Federal Reserve Bank of Minneapolis, Staff Report 249 . 
Kapetanios, G. and Yates, T.(2008), "An analysis of the great moderation in the UK and the US using a model of deterministic structural change", Bank of England, working paper.

Ireland, P. (2001), "Sticky price models of the business cycle: specification and stability" Journal of Monetary Economics, 47, 3-18.

Ireland, P. (2004), "Money's role in the monetary business cycle ", Journal of Money Banking and Credit, 36, 969-983.

Justiniano, A. and Primiceri, G. (2008), "Time varying volatility of macroeconomic fluctuations", American Economic Review, 56(1), 604-641

Leeper, E. and Zha, T. (2003), "Modest policy interventions", Journal of Monetary Economics, 50, 1673-1700.

Lubik, T. and Schorfheide, F. (2004), "Testing for Indeterminacy: with an application to US monetary policy", American Economic Review, 94, 190-217.

McConnell, M. and Perez Quiroz, G. (2000), "Output fluctuations in the US: what has changed since the early 1980s?", American Economic Review, 90, 1464-1476.

Roberts, J. (2006)," Monetary policy and inflation dynamics", International Journal of Central Banking, 2, 193-230.

Smets, F. and Wouters, R. (2003), " An estimated DSGE model for the Euro area", Journal of the European Economic Association, 1, 1123-1175.

Smets, F. and Wouters, R. (2007), "Shocks and Frictions in US Business Cycles: a Bayesian DSGE approach", American Economic Review 97(3), 586-606

Sargent, T. (1999) The Conquest of American Inflation, Princeton University Press, Princeton, N.J.

Sims, C.A. and Zha, T. (2006), "Were there regime switches in US monetary policy?", American Economic Review, 96, 54-81.

Stock, J. and Watson, M. (2002), "Has the business cycle changed and Why", NBER Macroeconomic annual, Cambridge, MIT Press, 159-218.

Woodford, M. (2003), Interest and Prices: Foundation of a Theory of Monetary Policy, Princeton University Press, Princeton, NJ. 


\section{A SW(2007) Model with non separable utility function}

In this section, we present some of the assumptions about preferences and technology of the the model of Smets and Wouters (2007), henceforth SW. Since many of the derivations are identical to SW, we only emphasize those that deviates from their setup. Household (HH) has a (non separable in money) utility function, i.e.

$$
U\left(C_{t}-h C_{t-1}, \frac{M_{t}}{e_{t} P_{t}}, L_{t}\right)=U\left(C_{t}-h C_{t-1}, \frac{M_{t}}{e_{t} P_{t}}\right)-V\left(L_{t}\right)
$$

Let $m_{t}=M_{t} / P_{t}$. HH budget constraint in real terms is

$m_{t}+C_{t}+I_{t}+\frac{B_{t}}{\epsilon_{t}^{b} R_{t} P_{t}}+T_{t}=m_{t-1} \frac{1}{\pi_{t}}+\frac{B_{t-1}}{P_{t-1}} \frac{1}{\pi_{t}}+\frac{W_{t}^{H H}}{P_{t}} L_{t}+\frac{R_{t}^{k}}{P_{t}} Z_{t} K_{t-1}-a\left(Z_{t}\right) K_{t-1}+\frac{\text { Div }^{P}}{P_{t}}+\frac{\text { Div }^{L}}{P_{t}}$

where $\operatorname{Div}^{P}$ and $D i v^{L}$ are dividends paid by the intermediate sector firms and labor unions. As in SW, labor unions pay a fixed wage to $\mathrm{HH}, W^{H H}$, differentiate $\mathrm{HH}$ labor and sell it to labor packers in a monopolistic competitive environment (profits are redistributed to $\mathrm{HH}$ in terms of dividends). Labor packers sell then "packed" labor to intermediate sector firms in a perfectly competitive market. The second constraint that HH faces is the capital accumulation law of motion, i.e.

$$
K_{t}=(1-\delta) K_{t-1}+\epsilon_{t}^{i}\left[1-S\left(\frac{I_{t}}{I_{t-1}}\right)\right] I_{t}
$$

The production side and the wage setting is identical to SW. Also the government budget constrain is similar with the only exception being money, i.e.

$$
G_{t}+\frac{B_{t}}{P_{t-1}} \frac{1}{\pi_{t}}+m_{t-1} \frac{1}{\pi_{t}}=T_{t}+\frac{B_{t}}{\epsilon_{t}^{b} R_{t} P_{t}}+m_{t}
$$

By adding money in the government budget constraint, the feasibility constrain is obtained simply by integrating across $\mathrm{HH}$ and adding gov't BC, and it is the same as SW, i.e.

$$
G_{t}+C_{t}+I_{t}+a\left(Z_{t}\right) K_{t-1}=Y_{t}
$$

In steady state, SW assume that $S(1)=0, S^{\prime}(1)=0, Z=1$ and $a(Z)=a(1)=0$. The steady state values are $R=1 / \beta \pi, r^{k}=1 / \beta-1+\delta, r^{k}=a^{\prime}(1), m c=\frac{1}{1+\epsilon^{p}}, w=$ $\left(\frac{\alpha^{\alpha}(1-\alpha)^{1-\alpha} m c}{\left(r^{k}\right)^{\alpha}}\right)^{\frac{1}{1-\alpha}}, L / Y=\frac{1-\alpha}{w}, K / Y=\frac{\alpha}{1 / \beta-1+\delta}, \Psi=(K / Y)^{\alpha}(L / Y)^{1-\alpha}$.

From the First Order Conditions (FOC) of the HH (taking the derivative of the objective function w.r.t. $C_{t}$ ) we obtain that

$$
U_{c}\left(C_{t}-h C_{t-1}, \frac{M_{t}}{e_{t} P_{t}}\right)=\theta_{t}
$$


Rewrite the RHS of the latter as

$$
U_{c}\left(\widetilde{C}_{t}, \widetilde{m}_{t}\right)=U_{c}(t)
$$

where $\widetilde{C}_{t}=C_{t}-h C_{t-1}$ and $\widetilde{m}_{t}=\frac{m_{t}}{e_{t}}$ and $m_{t}=\frac{M_{t}}{P_{t}}$. The partial derivative are

$$
\begin{aligned}
\frac{\partial U_{c}(t)}{\partial C_{t}} & =\frac{\partial U_{c}(t)}{\partial \widetilde{C}_{t}} \frac{\partial \widetilde{C}_{t}}{\partial C_{t}}=\frac{\partial U_{c}(t)}{\partial \widetilde{C}_{t}} \\
\frac{\partial U_{c}(t)}{\partial C_{t-1}} & =\frac{\partial U_{c}(t)}{\partial \widetilde{C}_{t}} \frac{\partial \widetilde{C}_{t}}{\partial C_{t-1}}=-\frac{\partial U_{c}(t)}{\partial \widetilde{C}_{t}} h \\
\frac{\partial U_{c}(t)}{\partial m_{t}} & =\frac{\partial U_{c}(t)}{\partial \widetilde{m}_{t}} \frac{\partial \widetilde{m}_{t}}{\partial m_{t}}=\frac{\partial U_{c}(t)}{\partial \widetilde{m}_{t}} \frac{1}{e_{t}} \\
\frac{\partial U_{c}(t)}{\partial e_{t}} & =-\frac{\partial U_{c}(t)}{\partial \widetilde{m}_{t}} \frac{\partial \widetilde{m}_{t}}{\partial e_{t}}=-\frac{\partial U_{c}(t)}{\partial \widetilde{m}_{t}} \frac{m_{t}}{e_{t}^{2}}
\end{aligned}
$$

At the steady state $(e=1)$, the partial derivatives are

$$
\begin{aligned}
\frac{\partial U_{c}}{\partial C_{t}} & =\frac{\partial U_{c}}{\partial \widetilde{C}_{t}}=U_{c c} \\
\frac{\partial U_{c}}{\partial C_{t-1}} & =-\frac{\partial U_{c}}{\partial \widetilde{C}_{t}} h=-h U_{c c} \\
\frac{\partial U_{c}}{\partial m_{t}} & =\frac{\partial U_{c}}{\partial \widetilde{m}_{t}} \frac{1}{e}=U_{c m} \\
\frac{\partial U_{c}}{\partial e_{t}} & =-\frac{\partial U_{c}}{\partial \widetilde{m}_{t}} \frac{m}{e^{2}}=-U_{c m} m
\end{aligned}
$$

The log linearized version of the FOC with respect to consumption is

$$
U_{c c} C \widehat{c}_{t}-h U_{c c} C \widehat{c}_{t-1}+U_{c m} m \widehat{m}_{t}-U_{c m} m \widehat{e}_{t}=\theta \widehat{\theta}_{t}
$$

From the steady state equation we have that $\theta=U_{c}$, the latter can be rewritten as

$$
\omega_{1} \widehat{\theta}_{t}=-\widehat{c}_{t}+h \widehat{c}_{t-1}-\omega_{2} \widehat{m}_{t}+\omega_{2} \widehat{e}_{t}
$$

where $\omega_{1}=-\frac{U_{c}}{C U_{c c}}$ and $\omega_{2}=\frac{m U_{c m}}{C U_{c c}}$.

From the FOC of the $\mathrm{HH}$ (taking the derivative w.r.t. $L_{t}$ ), we obtain

$$
V_{L}\left(L_{t}\right)=-\theta_{t} W_{t}^{H H} / P_{t}=-\theta_{t} w_{t}^{H H}
$$

where $W_{t}^{H H}$ is the wage paid by the Unions to the household. At the steady state,

$$
V_{L}=-\theta W^{H H} / P
$$


The log linear version of the FOC w.r.t. $L_{t}$ is

$$
\begin{gathered}
V_{L L} L \widehat{l}_{t}=-\theta w^{H H} \widehat{\theta}_{t}-\theta w^{H H} \widehat{w}_{t}^{H H} \\
\omega_{3} \widehat{l}_{t}=\widehat{\theta}_{t}+\widehat{w}_{t}^{H H}
\end{gathered}
$$

where $\omega_{3}=-\frac{V_{L L} L}{V_{L}}$.

Finally, the FOCs of the HH with respect to $m_{t}=M_{t} / P_{t}$ and $b_{t}=B_{t} / P_{t}$ are

$$
\begin{aligned}
U_{m}\left(C_{t}-h C_{t-1}, \frac{M_{t}}{e_{t} P_{t}}\right) & =\theta_{t}-\beta E_{t}\left(\theta_{t+1} \frac{1}{\pi_{t+1}}\right) \\
\theta_{t} \frac{1}{\epsilon_{t}^{b} R_{t}} & =\beta E_{t}\left(\theta_{t+1} \frac{1}{\pi_{t+1}}\right)
\end{aligned}
$$

combining the two we obtain

$$
U_{m}\left(C_{t}-h C_{t-1}, \frac{M_{t}}{e_{t} P_{t}}\right)=\theta_{t}\left[1-\frac{1}{R_{t} \epsilon_{t}^{b}}\right]
$$

At the steady state,

$$
U_{m}\left(C(1-h), \frac{M}{P}\right)=\theta\left[1-\frac{1}{R}\right]
$$

Log linearization implies

$$
\begin{gathered}
U_{m c} C \widehat{c}_{t}-h U_{m c} C \widehat{c}_{t-1}+U_{m m} m \widehat{m}_{t}-U_{m m} m \widehat{e}_{t}=\theta\left[1-\frac{1}{R}\right] \widehat{\theta}_{t}+\theta \frac{1}{R^{2}} R \widehat{r}_{t}+\theta \frac{1}{R} \widehat{\epsilon}_{t}^{b} \\
U_{m c} C \widehat{c}_{t}-h U_{m c} C \widehat{c}_{t-1}+U_{m m} m \widehat{m}_{t}-U_{m m} m \widehat{e}_{t}=\theta\left[1-\frac{1}{R}\right] \widehat{\theta}_{t}+\theta \frac{R-1}{R(R-1)} \widehat{r}_{t}+\theta \frac{R-1}{R(R-1)} \widehat{\epsilon}_{t}^{b} \\
U_{m c} C \widehat{c}_{t}-h U_{m c} C \widehat{c}_{t-1}+U_{m m} m \widehat{m}_{t}-U_{m m} m \widehat{e}_{t}=U_{m} \widehat{\theta}_{t}+\frac{U_{m}}{R-1} \widehat{r}_{t}+\frac{U_{m}}{R-1} \widehat{\epsilon}_{t}^{b}
\end{gathered}
$$

dividing for $U_{m}$ we get

$$
\begin{gathered}
\frac{U_{m c} C}{U_{m}} \widehat{c}_{t}-h \frac{U_{m c} C}{U_{m}} \widehat{c}_{t-1}+\frac{U_{m m} m}{U_{m}} \widehat{m}_{t}-\frac{U_{m m} m}{U_{m}} \widehat{e}_{t}=\widehat{\theta}_{t}+\frac{1}{R-1} \widehat{r}_{t}+\frac{1}{R-1} \widehat{\epsilon}_{t}^{b} \\
-\omega_{5} \widehat{c}_{t}+h \omega_{5} \widehat{c}_{t-1}-\omega_{4} \widehat{m}_{t}+\omega_{4} \widehat{e}_{t}=\widehat{\theta}_{t}+\frac{1}{R-1} \widehat{r}_{t}+\frac{1}{R-1} \widehat{\epsilon}_{t}^{b}
\end{gathered}
$$

where $\omega_{5}=-\frac{C U_{m c}}{U_{m}}$ and $\omega_{4}=-\frac{m U_{m m}}{U_{m}}$.

The remaining log linearized equations are derived similarly as in SW. 

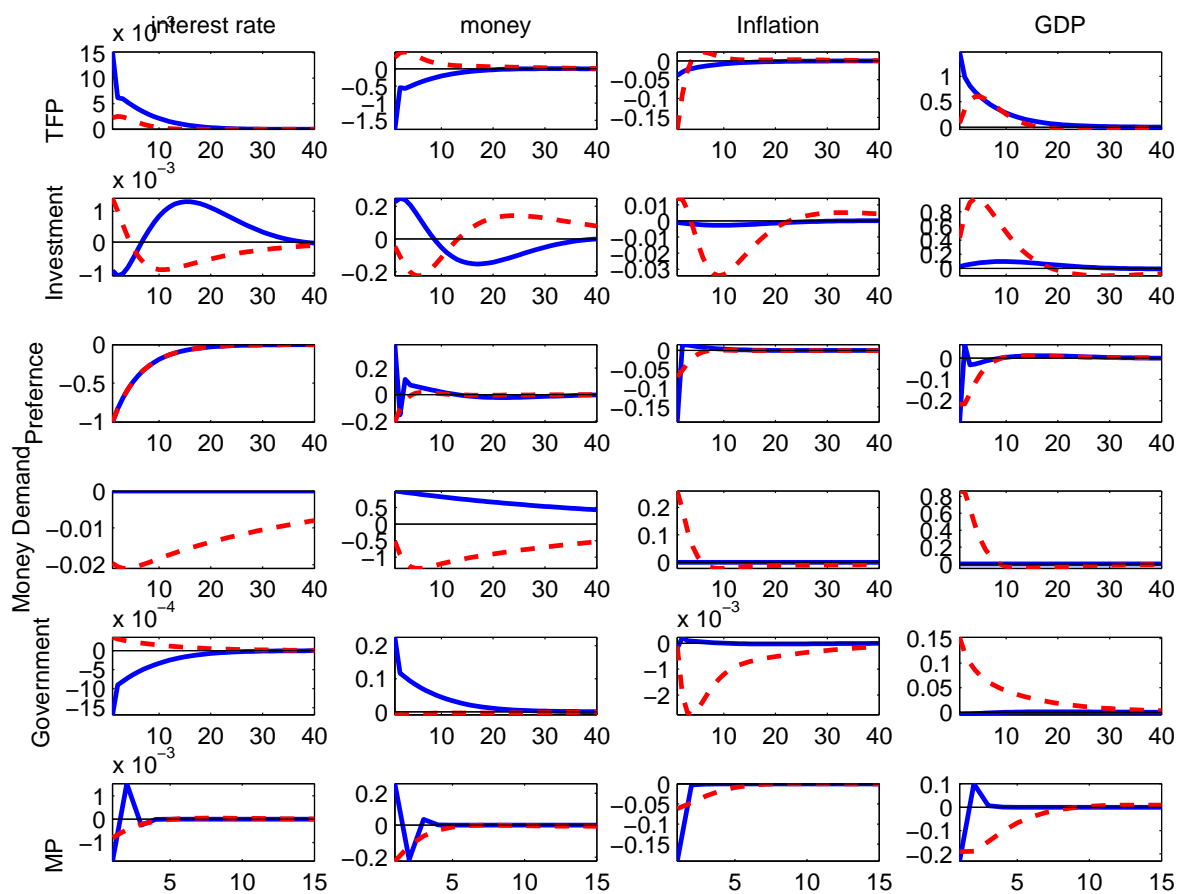

Figure 10: Impulse responses for the model with $\omega_{2}=\omega_{5}=0$ and with $\lambda_{m}=0$. Form top to bottom, TFP, Investment, Preference, Money Demand, Government, Monetary Policy. 

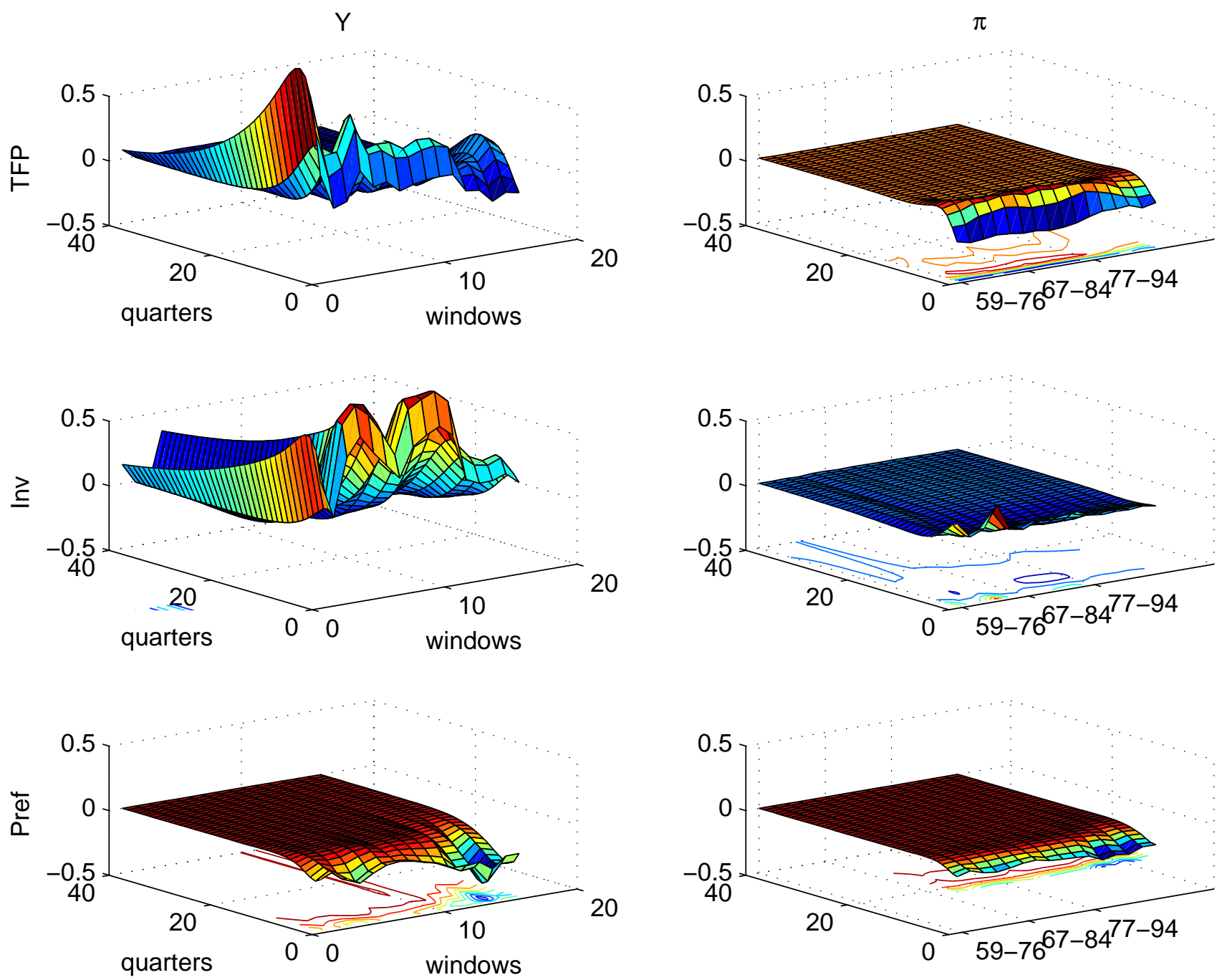

Figure 11: Impulse response of output and inflation to shocks. 

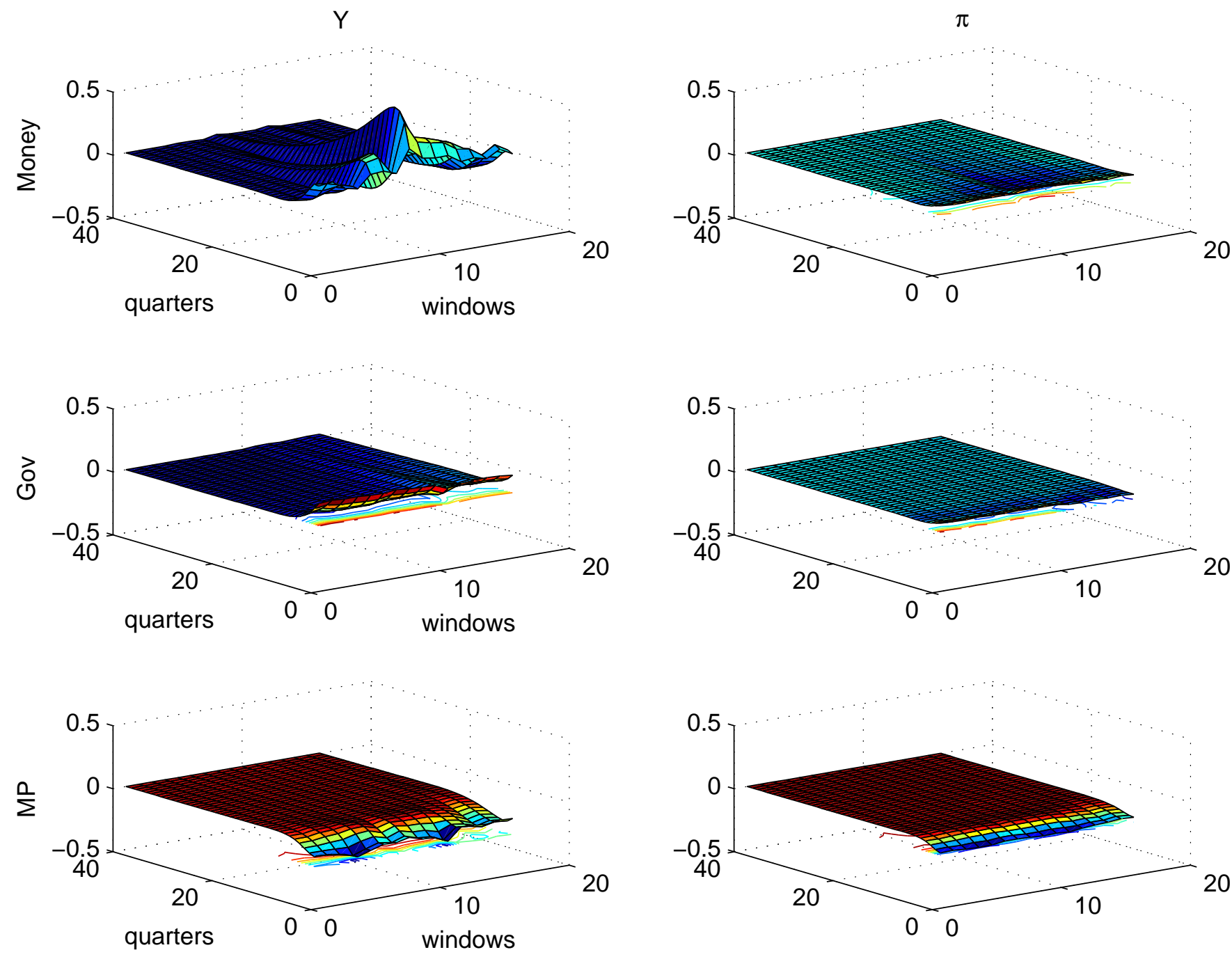

Figure 12: Impulse response of output and inflation to shocks. 


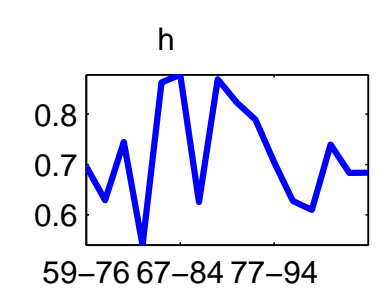

$\omega_{4}$

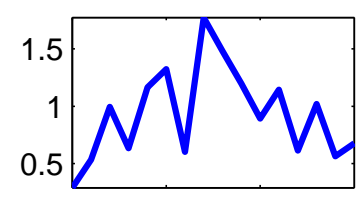

59-76 67-84 77-94

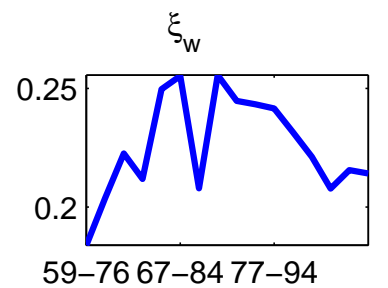

$\lambda_{r}$

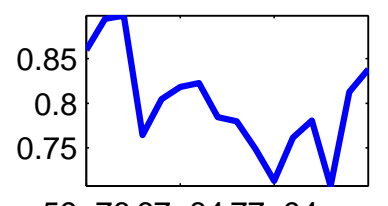

59-76 67-84 77-94 $\omega_{1}$

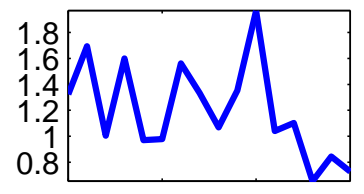

59-76 67-84 77-94

$\omega_{5}$

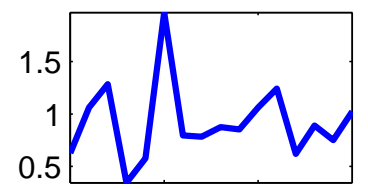

59-76 67-84 77-94

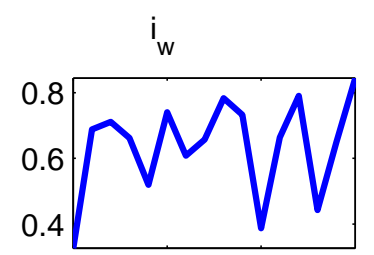

59-76 67-84 77-94

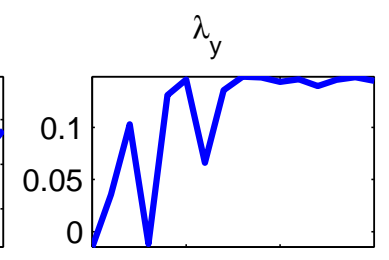

59-76 67-84 77-94

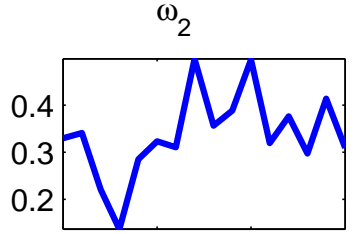

59-76 67-84 77-94

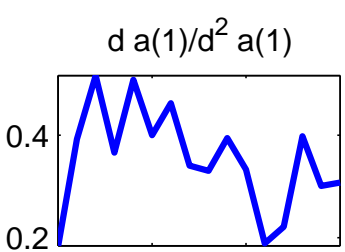

59-76 67-84 77-94

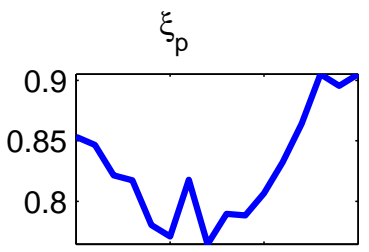

59-76 67-84 77-94

$\lambda_{\mathrm{m}}$

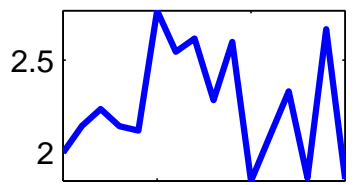

59-76 67-84 77-94 $\omega_{3}$

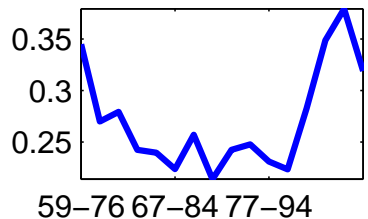

$d^{2} S(1)$

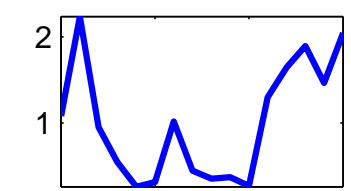

59-76 67-84 77-94

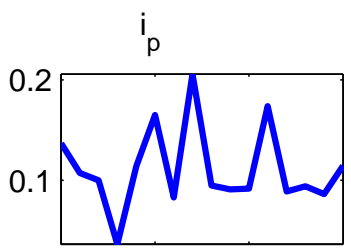

59-76 67-84 77-94 $\lambda_{\pi}$

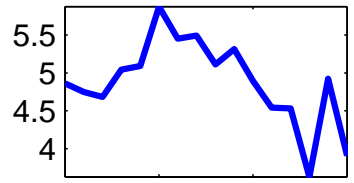

59-76 67-84 77-94

Figure 13: Rolling parameter estimates. 

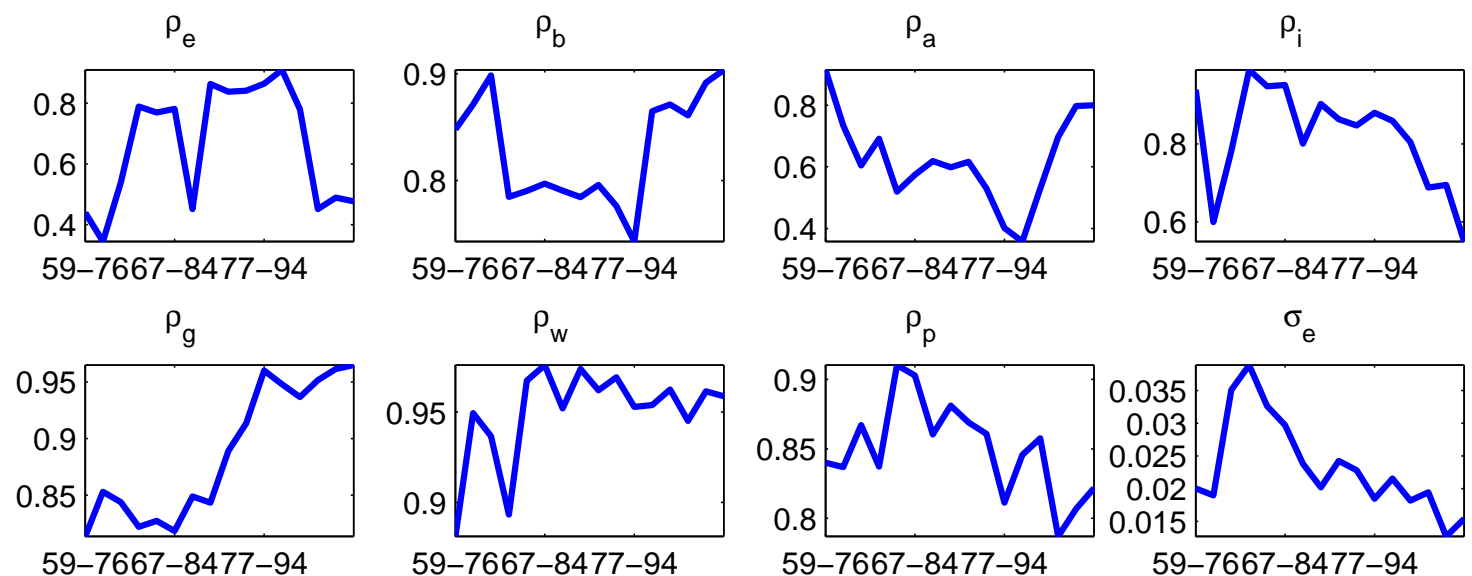

59-7667-8477-94
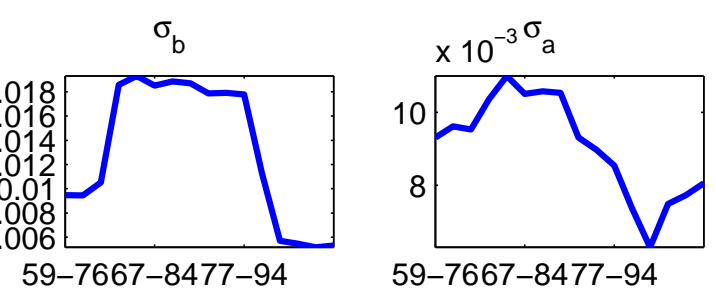

59-7667-8477-94
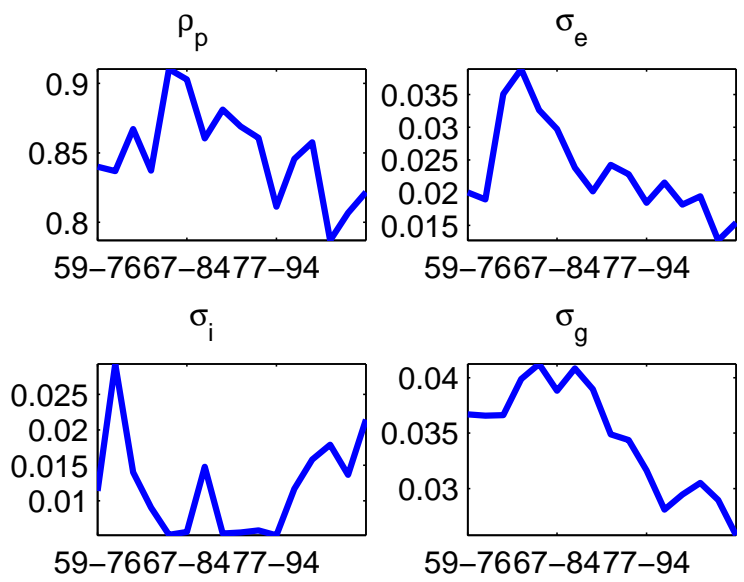

59-7667-8477-94
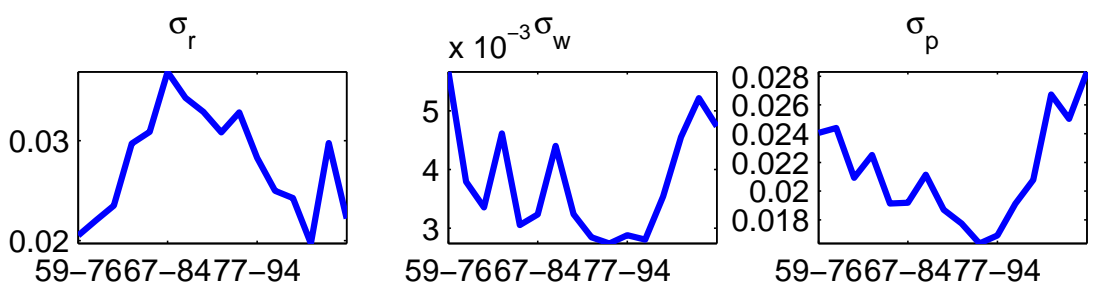

Figure 14: Rolling parameter estimates.

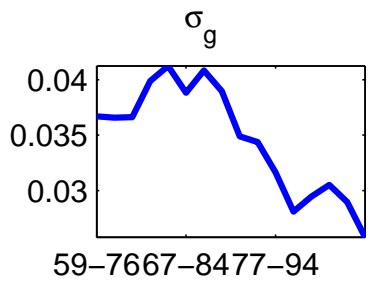

